\title{
Democratisation under Diversity: Theory and Evidence from Indonesian Communities
}

\author{
By Anirban Mitra And SARmistha PAL ${ }^{1}$
}

SEPTEMBer 2020

\begin{abstract}
We study the effect of ethnic diversity on local public spending following fiscal decentralisation in a setting where local institutions are salient. Specifically, the latter affects coordination costs and thereby cooperative behaviour across the constituent ethnic groups. Our theory highlights the role of the local elite in lobbying for policies which favour them in a decentralised setting. The differences in preferences over public good allocations along with the salience of coordination costs across ethnic groups are relevant in determining the equilibrium lobbying behaviour. This results in ethnic diversity having a detrimental effect on local developmental spending which is aggravated by increased levels of coordination costs. We test these predictions using Indonesian community-level data. Utilising the 1997 and 2007 Indonesian Family Life Survey (IFLS) rounds, we are able to construct various measures of ethnic diversity. We exploit an institutional feature of Indonesian communities namely, the observance of traditional "Adat" laws to proxy coordination costs across ethnic groups. Overall, we find that ethnic diversity depresses local development spending postdecentralisation at the community level particularly where Adat laws are not followed, which is consistent with our theory.
\end{abstract}

JEL codes: D72, D74, H40

Keywords: Decentralisation, Lobbying, Local development, Political Economy.

\footnotetext{
${ }^{1}$ We are grateful to Scott Gates, Bård Harstad, Halvor Mehlum, Zaki Wahhaj and to the various participants at the 15th PEARL Workshop on Public Economics (Zermatt, Switzerland), the 14th Annual Conference on Economic Growth and Development at ISI Delhi (New Delhi, India), Political Economy Workshop at the University of Oslo (Norway), the European Public Choice Society Meeting 2019 (Jerusalem, Israel), the XXIXth Annual Conference on Contemporary Issues in Development Economics at Jadavpur University (Calcutta, India), IIM Calcutta seminar series (India), Applied Microeconomics Research Day at the University of Kent (UK), the Aix-Marseille School of Economics Development seminar series (France) and the XVth CPP Conference at IIM Bangalore for useful comments. The usual disclaimer applies. Mitra: University of Kent; Pal: University of Surrey.
} 


\section{Introduction}

An important precondition for good governance is the degree of community homogeneity. This finds fervent mention in the writings of John Stuart Mill (1861: p.289): "among a people without fellow-feeling, the united public opinion necessary to the working of representative government cannot exist." More recently, Easterly and Levine (1997) argued that diverse societies cannot agree on needed public goods and are more likely to engage in rent-seeking activities. Collier (2008) too points out that ethno-linguistic fractionalisation reduces trust, increases transactions costs and adversely affects development in general. Some argued that decentralisation at the local level may reduce the adverse effects of diversity (e.g., Azfar et al. 2001). This is because the extent of diversity is likely to be lower at the local than at the national level. Also, decentralisation that involves a certain devolution of powers to local agents may promote democracy and increase accountability to local people. However elite capture may not be ruled out in decentralised settings (Bardhan and Mookherjee, 2000). This is more so when the centre retains the bulk of resources, which may lead to lobbying, bargaining and the consequent uncertainty in the process of development.

While much of the work on the link between diversity and development is done at the countrylevel, how community governance and local development may vary across ethnically diverse communities post-decentralisation remains relatively under-explored. The present paper raises - and attempts to address - the following question. Is the (negative) relationship between ethnic diversity and local development substantially affected by local institutional features following the implementation of decentralisation? By local institutions we refer the norms of behaviour governing all the members of the local community across the constituent ethnic groups. ${ }^{2}$

We explore the inherent trade-off between the gains from decentralisation and the losses from local elite capture in a setting with ethnic diversity. Undoubtedly, ethnic diversity implies a certain difference in the preferences over public goods. However, different ethnic groups may well have difficulties in coordinating over collective activities alongside there being any intrinsic taste differences. This creates a role for local institutions which may affect these coordination costs by promoting an ethic of mutual cooperation and engagement.

To develop this idea precisely, we utilise a simple model of lobbying where society has citizens with different preferences over local public spending. In our framework, there is an elite group and the remaining citizens - namely, the non-elites - are divided into two ethnic groups. Thus, like in Bandiera and Levy (2011) there is diversity in terms of social class (elite/non-elite) and in terms of ethnic preferences (within the non-elites). Ethnic diversity in our model stems from the difference in sizes of the different ethnic groups. Diversity in taste arises since each group has its own most-preferred allocation of the (local) public funds which are all - in principle - distinct across the groups.

\footnotetext{
${ }^{2}$ This will be made clear below in the context of the specific empirical setting that we analyse.
} 
The main idea is the following. Fiscal decentralisation - by increasing the influence of the local politician — raises the interest of the community in being able to "influence" the same. To do so, the elite may exert itself as a lobby or it could involve one of the two ethnic groups in the lobby as well. The local politicians are keen on garnering support from the community and, in the absence of a lobby, would simply implement the benevolent planner's policy. However, the lobby by exerting itself may be able to tilt policy in favour of the lobby group. In equilibrium, there arises a distortion in policy in relation to that of the benevolent planner's with a positive probability. We highlight the factors which affect the extent of this distortion. In particular, our simple model demonstrates that taste diversity/coordination costs across the different ethnic groups, i.e., factors pertaining to local institutions are crucial elements. In a sense, the elite are able to exploit this difference across the ethnic groups to distort spending to their advantage. This, in turn, implies that any local institutional feature which can affect these coordination costs will change the scope of the distortion in local public policy.

In reality, however, one typically does not have a clear empirical measure of coordination costs relating to local public policy across various ethnic groups. This is precisely why Indonesian communities provide an ideal setting for examining these nuanced differences. The presence of the Adat custom will allow us to utilise adherence to Adat laws as implying high level of mutual interaction and cooperation within the community. The Adat system relies heavily on the notion of "consensus building" ( musyawarah) which involves community members to engage in group deliberation leading to consensus in communal matters. We are furthermore able to see these forces at play more clearly, owing to the 2001 decentralisation which allowed the local elites within the communities a chance to organise themselves and lobby. Our model predicts that in the post-decentralisation period, ethnic diversity will adversely affect developmental spending — owing to elite capture - at the community level particularly in communities which eschew Adat customs (hence, 'non-adat').

Fiscal decentralisation in post-Suharto Indonesia was largely an exogenous event for the communities, which has its roots in Law 22/99 and Law 25/99 enacted in January 2001. It gave local communities more autonomy in raising local revenues while enforcing strict budgetary cuts on the central leadership to supply development grants to these communities. It also granted administrative authority to local governments to hire staff and conduct local government affairs with a minimum intervention of the central government. Local community governments were made responsible to the district government who provided the bulk of their funds after fiscal decentralisation; in other words, the centre of power moved from the central government in Jakarta to the district governments located in district head-quarters after fiscal decentralisation. We study the local communities at 1997 and at 2007 - two junctures separated by the introduction of fiscal decentralisation in 2001. Our analysis is based on the community level data obtained from 1997 and 2007 Indonesian Family Life Survey (IFLS) from 312 rural and urban communities, drawn from 13 provinces. These waves allow for a pre and post study vis-a-vis the fiscal decentralisation policy. 
We observe the size of the top three population groups in the sample communities which we use to construct indices of ethnic diversity. ${ }^{3}$ We also utilise the information about the community's adherence to Adat norms. Adat law was recognised by the colonial administration in the Dutch Indies as part of a dual legal system in which natives were subject to 'their own religious laws, institutions and customs so far as they were not in conflict with generally recognized principles of equity and justice ...' (Fasseur 2007). Based on the knowledge and information of a local expert, the Indonesian Family Life Surveys (IFLS) classified all communities in terms of their adherence to adat laws. Since adherence to adat laws in sample communities has not remained stable during 1997-2007, we classify communities as "stable adat" if and only if these communities strictly adhere to adat laws in both waves of the IFLS survey. Pal and Wahhaj (2017) have shown the close correspondence between strict adherence to adat and the ethic of mutual cooperation of communities in various activities including public infrastructure projects. Accordingly, we envisage that stable adat reflects lower coordination costs across the various ethnic groups within the community, while its complement non-adat (that accounts for by an absence of strict adherence to adat norms in both 1997 and 2007) reflects higher costs of cooperation and coordination in our context.

The IFLS data also provide information on the spending allocation of the local community government in both 1997 and 2007 rounds. Total spending has the following components: (i) development spending refers to spending on new social (e.g., local schools and health centres) and physical (e.g., roads and transport) infrastructure as well as maintenance of existing infrastructure; (ii) non-development spending includes spending on staff salary, office maintenance, official trips and contingencies; (iii) some under-developed communities also receive grants for various developmental programs, e.g., IDT for under-developed communities. Accordingly, we are able to construct different measures of development spending (valued by the poor/non-elite) and also non-development spending (valued by the elite).

Using these data, we are able to test the models predictions for local public spending. We compare communities characterised - within a district - by different levels of ethnic diversity and Adat adherence, before and after the exogenous introduction of fiscal decentralisation. ${ }^{4}$ In our empirical analysis, we consistently find that communities which do not strictly follow Adat laws and are ethnically diverse tend to have lower levels of development spending at the community level after controlling for a host of explanatory variables. Moreover, the effect on the spending on non-development categories (like the salaries of local leaders and their administrative expenses, etc.) is in the opposite direction. Thus, these empirical findings align very closely with our theoretical predictions.

These key findings survive a battery of robustness checks: e.g., they extend to the use of social and physical infrastructure spending at the community level, they prevail when using the shares (out of total public spending) of the different variables in conjunction with the

\footnotetext{
${ }^{3}$ The top three population groups form nearly $100 \%$ of the community's population in all cases.

${ }^{4}$ Our identification strategy is explained in greater detail under Section 3.6.
} 
levels of spending under the various heads, they also are consistent across different measures of ethnic diversity. All these results consistently exhibit the same pattern, namely, that of elite capture in such communities in the aftermath of fiscal decentralisation.

Our contribution intertwines with various strands of the literature. The literature on ethnic diversity and development revolves around the general consensus that ethnic diversity is detrimental to development (Easterly and Levine, 1997; Alesina et al. 1999; Banerjee and Somanathan, 2007; Collier 2008). More recently, Ashraf and Galor (2013) point out that diversity could have both positive and negative impacts on economic outcomes. It is argued that there exists an optimal level of diversity for each stage of economic development, reflecting the interplay between the opposing effects of diversity on the development process. The adverse effect pertains to the detrimental impact of diversity on the efficiency of the aggregate production process. The beneficial effect of diversity, on the other hand, concerns the positive role of heterogeneity in the expansion of societys production possibility frontier. A wider spectrum of traits is more likely to contain those that are complementary to the advancement and successful implementation of superior technological paradigms. In a similar vein, Gomes (2020) argues that ethnic diversity leads to a higher stock of knowledge in society about how to rear ones children and thus improves the health outcomes of children, whereas individual ethnic distances act as barriers to accessing such knowledge and thus lead to worse health outcomes. Our stand is that adherence to adat norms in Indonesia may induce co-operation even in diverse societies.

The literature on decentralisation is sizeable and diverse. Some of this literature tends to analyse the effects of some aggregate measure of decentralisation on public policy and development in cross-country setup. Some use cross-sectional (see for example, Davoodi and Zou (1998), De Luca et al. (2002), De Mello and Barenstein (2001) and Fishman and Gatti (2002)) while others use panel (Enikolopov and Zhuravskaya (2007)) data. In particular, Enikolopov and Zhuravskaya (2007) show that fiscal decentralisation is more successful in those economies which are more politically decentralised. They, however, do not investigate the nature and variation of political decentralisation across the sample countries.

Additionally, there is the literature - mostly in the fields of political science and economics - on democratic capture by the elite or other interest groups by means of vote buying, voter co-optation, patronage networks, and the use of force or its threat (e.g., see Bardhan, 2002; Bardhan and Mookherjee, 2006) at a more local level. Besley et al. (2005) assess the role of individual characteristics of the local politicians on the quality of decentralised governance. They find that education increases the likelihood of selection to public office and reduces the odds that a politician uses political power opportunistically. As such, these afore-mentioned studies do not directly focus on identifying the role of fiscal decentralisation in determining the pattern of local public policy in ethnically diverse communities.

In terms of the work on Indonesia, Martinez-Bravo (2014) assesses the impact of the first post-Soeharto parliamentary election in Indonesia to test if new democracies experience 
greater electoral fraud and more clientelistic spending than established democracies. Using both village and district-level Indonesian data over 1999-2002, she shows that the body of appointed local officials that a new democracy (predominantly the urban ones) inherited from the previous regime is a key determinant of the extent of these practices. Relatedly, Martinez-Bravo, Mukherjee and Stegmann (2017) show that allowing old-regime agents to remain in office during democratic transitions is a key determinant of the extent of elite capture. Soeharto-regime mayors were allowed to finish their terms before being replaced by new leaders. Since mayors political cycles were not synchronized, this event generated exogenous variation in how long old-regime mayors remained in their position during the democratic transition. Districts with longer exposure to old-regime mayors experience worse governance outcomes, higher elite persistence, and lower political competition in the medium run. Their results suggest that slower transitions towards democracy allow the old-regime elites to capture democracy. Their findings being largely concerned with the political ramifications of decentralisation (old-regime mayors lead to lower political competition, etc.) provide a complementary dimension to our approach which is about the fiscal aspect of decentralisation. Additionally, their mechanism does not involve the aspect of ethnic divisions.

Next, we briefly dwell upon two papers which are closest to our work. Bandiera and Levy (2011) examine if political outcomes in local democracies are determined by the preferences of the median, typically poor agents, or that of the rich elite. Their theoretical setup builds on a citizen-candidate type model where coalitions are allowed. The main prediction is that in ethnically diverse societies, the elite are able to offer a platform which defeat the one most preferred by the poor (non-elite) as a whole. Hence, they are able to distort policy in their favour owing to the difference in ethnicity-based preferences among the nonelite. Their empirical analysis using the 1997 Indonesian Family Life Survey data reveals that democratic policy outcomes are closer to the elite preferences in ethnically diverse decentralised communities. The other is Padro-i-Miquel et al. (2014) who examine the case of rural China. They demonstrate that one of the preconditions for exogenously introduced grassroots democracy to be effective is the degree of community homogeneity in some vertical attribute (religion in their case) that allows better provision of public goods. In particular, they find that voter heterogeneity constrains the potential benefits of elections for public goods provision.

While closely related to these two papers, our work makes a marked departure in that we show how ethnically diverse communities may benefit less from fiscal (as opposed to political) decentralisation owing to the strategic actions of the local elite when coordination costs across ethnic groups are salient. In this respect, we explore the heterogeneous effects of fiscal decentralisation on local development spending. We are able to pinpoint a specific mechanism linking ethnic diversity to local developmental spending post-decentralisation highlighting the role of local institutions; in the empirical analysis this is operationalised by utilising a unique institutional feature of Indonesian communities - namely, Adat laws. 
The remainder of the paper is organised as follows. Section 2 presents a simple model designed to address our main questions. Section 3 describes the data, the empirical strategy and findings and Section 4 concludes. All proofs are contained in the appendix.

\section{Theory}

Here we set up a simple model to study the potential effects of decentralisation upon local public spending at the community level. Decentralisation increases the influence of the local politician. This, in turn, implies that the community as a whole recognise that controlling the local politician is valuable. This potentially spurs the constituent ethnic groups within the community to lobby together in order to influence the local politician. However, the degree of diversity inherent in society - be it in terms of taste or ethnicity - affects the coordination efforts by influencing the potential gains and the costs of cooperation.

\section{$2.1 \quad$ A Model}

In our model, there is a local politician $(L)$ and two constituent social groups within the village community - call them $E$ and $C$, where the former denote the (local) elite and the latter the non-elite citizens. We will assume that the mass of the elites is $\lambda$ which lies between $(0,1 / 2)$ and that of the non-elite citizens is $1-\lambda$. Furthermore, the non-elites are divided into two distinct ethnic groups. Suppose $\rho \in[1 / 2,1)$. Let $\rho(1-\lambda)$ denote the size of the larger ethnic group while the smaller group is of mass $(1-\rho)(1-\lambda)$. We shall call them $C_{1}$ and $C_{2}$, respectively, so that $C_{1} \cup C_{2}=C$. This division of the village community along class (elite/non-elite) and ethnic lines (two groups within the non-elite) is similar to the one in Bandiera and Levy (2011).

A major distinction across the three socio-economic groups arises from their preferences over the allocation of (local) public goods - which, post-decentralisation, depends upon the extent to which either group can influence $L$. Let us say that post-decentralisation there is a quantity of funds (the local budget) which is in the hands of $L$. Call this amount $R$ which is assumed to be strictly positive. Now depending upon the efforts of a lobby (if any arises), the distribution of the local public goods will be determined. We assume that the elite $E-$ by virtue of it's social standing - has a first-mover advantage in deciding the composition of the lobby.

If the elite decide to lobby alone and are successful, then they get to enjoy $R$ solely by themselves - thus the members of $C_{1}$ and $C_{2}$ are deprived of this public spending. Alternatively, $E$ could strategically decide to involve one of these two groups in the lobby and exclude the third one. In the latter situation ( $E$ and either $C_{1}$ or $C_{2}$ jointly lobby), the total value of the resources $R$ is assumed to diminish to $R \alpha$, where $\alpha \in(0,1)$. One could think of $\alpha$ 
embodying the extent of alignment of preferences among $E$ and the non-elite group over (local) public spending. Alternatively, $\alpha$ may be considered as a proxy for the coordination costs for collective action between the rich and the poor. Either interpretation is valid for the context we study. A similar preference factor/coordination cost parameter exists for cooperation between the two poor but ethnically distinct groups. This is reflected by the parameter $\beta$, where $\beta \in(0,1)$.

In case no lobby is able to successfully influence $L$, then they each get a baseline payoff of $R \alpha \beta$. Think of the resulting mix of public goods as one which is like a 'compromise' bundle - hence providing each group with a payoff no higher than what their (respective) optimal mix of public goods would bring, at the same time being 'fair' in a sense. Alternatively, one could think that $L$ wishes to maximise his popularity because of electoral incentives and hence offers this bundle which excludes nobody. In this scenario, $L$ retains the surplus from having complete influence over local spending which provides $L$ a payoff of $U>0$.

Another way to interpret these lobbying possibilities is to consider the scenario where the district authorities - rather than $L$ - is in charge of allocation of funds to each of these villages/communities. In this setting, lobbying by any group would mean that they are trying to influence the district authority about the allocation and their efforts are being resisted by the local politician who wishes to utilise these rents (handed down from the district level) to further his private interests.

The sequence of events in this game is as follows.

(i) The elite group, $E$, moves first and decides amongst the following actions: lobby alone, suggest lobbying jointly to either $C_{1}$ or $C_{2}$, or not lobby.

(ii) In case $E$ suggests joint lobbying, the other group can either accept or refuse. In the latter case, $E$ can either lobby singly or not at all.

(iii) Based on $C_{1}, C_{2}$ and $E$ 's lobbying decisions, $L$ decides to resist or not.

(iv) If the citizens decide not to lobby, then $L$ gets allots the funds equally - so all groups get a payoff of $R \alpha \beta$. The same outcome (i.e., funds shared equally/no exclusion) accrues if $L$ wins the contest. Otherwise the winner(s) of the lobbying game get to exclude the non-lobbyists.

The outcome of the lobbying is determined by a contest success function which will be made clear shortly.

Before proceeding further, it is necessary to highlight some key features of our simple model. There is a distinction between ethnic diversity (as measured by the population sizes of the ethnic groups) and diversity over the preferences over public funds usage. The former is captured by the parameter $\rho$, which denotes the ethnic cleavage within the non-elites. The latter manifests itself in the tension between what is optimal for a specific subgroup and what is optimal for the entire community — it is enshrined in the extent of compromising 
that needs to be done when lobbying alongside others. In our setup, this type of diversity is effectively captured by two parameters, namely, $\alpha$ and $\beta$. The closer either is to unity, the smaller the differences in taste between the various groups.

Another feature which is relevant concerns the identity of the elite. We envisage the elite as a group of citizens who possibly have higher incomes than the rest and certainly wield more political influence than the others. To be sure, this political influence may stem from their holding positions of economic power. Relatedly, the higher economic stakes may well impel these wealthier citizens to lay aside their differences and form a more active lobby group which can react more quickly to the changing political scenario than the rest. While this interplay of economic and political factors is no doubt important, we abstract away from developing this connection more fully and simply endow this minority group $E$ with a first-mover advantage.

Furthermore, in our setup, the political arrangement for "sharing" the local budget prior to decentralisation is not pertinent for the equilibrium after decentralisation. This is because that prior arrangement is not a "default option" for any of the players - there is no possibility of any group threatening to revert to the original (i.e., pre-decentralisation) arrangements.

Next, we describe the payoffs in each of the possible subgames which follow from E's choice at the step (i).

We assume that there is a group leader within each group $-C_{1}, C_{2}$ or $E-$ who decides on the effort/resources for lobbying on behalf of the group; all the members of the group then contribute according to this decision. This is essentially to rid ourselves of the standard free-rider problem. ${ }^{5}$ The group leader chooses the effort level with the aim of maximising the expected per-capita payoff to the group just like in Esteban and Ray (2008).

In the case that the local leader $L$ decides to resist the lobby, we will assume that he does so with the same intensity regardless of the identity of the lobby. This simplifying assumption signifies that $L$ is non-partisan in the sense that any lobby opposing the egalitarian allocation is opposed with equal vehemence. Call this resistance effort $e(L)$ which we normalise to unity.

We start with the case where $E$ chooses to lobby alone.

\section{Case (A): E lobbies alone}

Here $E$ 's problem is to choose the effort level $e$ to maximise

$$
\left[\frac{1}{\lambda e+1}\right] R \alpha \beta+\left[\frac{\lambda e}{\lambda e+1}\right] \frac{R}{\lambda}-\psi e .
$$

\footnotetext{
${ }^{5}$ This approach is quite common in such types of games. See Esteban and Ray (1999), (2008) among others.
} 
The opposition stems from $L$ 's effort of unity. $E$ wins with probability $\frac{\lambda e}{\lambda e+1}$ and shares the entire budget amongst its members - hence the $R / \lambda$ term. In case $L$ is able to successfully repel the lobby, the former's preferred egalitarian mix of public spending is provided which yields $R \alpha \beta$ to every citizen.

Of course, such lobbying is costly and to capture this we introduce a linear cost of $\psi e$ where the parameter $\psi$ is positive.

\section{Case (B): $E$ and $C_{1}$ lobby jointly}

Here the total value of the resources $R$ is assumed to diminish to $R \alpha$, where $\alpha \in(0,1)$ captures the coordination costs or divergence in preferences over public spending. We posit that the elite are able to corner a larger share of the resources - we capture this asymmetry with a single parameter $\theta>1$. Also, we assume that they contract between themselves to supply the same level of effort per-capita. Call this $e$.

Like before, $L$ opposes with effort equals unity. So the payoff to $E$ is given by

$$
\left(\frac{[\lambda+\rho(1-\lambda)] e}{[\lambda+\rho(1-\lambda)] e+1}\right)\left(\frac{R \alpha \theta}{\lambda+\rho(1-\lambda)}\right)+\left(\frac{1}{[\lambda+\rho(1-\lambda)] e+1}\right) R \alpha \beta-\psi e .
$$

To ensure that the above is strictly concave in $e$, we assume that $\alpha \theta>1$.

The payoff to group $C_{1}$ is given by

$$
\left(\frac{[\lambda+\rho(1-\lambda)] e}{[\lambda+\rho(1-\lambda)] e+1}\right)\left(\frac{R \alpha s_{1}}{\lambda+\rho(1-\lambda)}\right)+\left(\frac{1}{[\lambda+\rho(1-\lambda)] e+1}\right) R \alpha \beta-\psi e,
$$

where $s_{1}<1$ is the share obtained after adjusting for the larger share $(\theta)$ taken by $E$. As $R \alpha$ is divided among (unequally) among $E$ and $C_{1}$, it must satisfy the following restriction:

$$
\theta \lambda\left(\frac{R \alpha}{\lambda+\rho(1-\lambda)}\right)+s_{1} \rho(1-\lambda)\left(\frac{R \alpha}{\lambda+\rho(1-\lambda)}\right)=R \alpha
$$

This yields the following expression for $s_{1}$.

$$
s_{1}=1-\frac{\lambda(\theta-1)}{(1-\lambda) \rho}
$$

It is worth emphasizing that the effort $e$ is chosen by $E$ but $C_{1}$ has the right to refuse this contract if the group feels it is better off by not lobbying. 


\section{Case (C): $E$ and $C_{2}$ lobby jointly}

The situation is similar to Case (B). The payoffs are analogous - one simply needs to adjust for the group size $\left(C_{2}\right.$ instead of $\left.C_{1}\right){ }^{6}$ So the payoff to $E$ is given by

$$
\left(\frac{[\lambda+(1-\rho)(1-\lambda)] e}{[\lambda+(1-\rho)(1-\lambda)] e+1}\right)\left(\frac{R \alpha \theta}{\lambda+(1-\rho)(1-\lambda)}\right)+\left(\frac{1}{[\lambda+(1-\rho)(1-\lambda)] e+1}\right) R \alpha \beta-\psi e .
$$

The payoff to group $C_{1}$ is given by

$$
\left(\frac{[\lambda+(1-\rho)(1-\lambda)] e}{[\lambda+(1-\rho)(1-\lambda)] e+1}\right)\left(\frac{R \alpha s_{2}}{\lambda+(1-\rho)(1-\lambda)}\right)+\left(\frac{1}{[\lambda+(1-\rho)(1-\lambda)] e+1}\right) R \alpha \beta-\psi e
$$

where $s_{2}<1$ is the share obtained after adjusting for the larger share $(\theta)$ taken by $E$. Straightforward accounting delivers the following:

$$
s_{2}=1-\frac{\lambda(\theta-1)}{(1-\lambda)(1-\rho)} .
$$

\section{Case (D): Nobody lobbies}

Each of the groups get the same payoff which is $R \alpha \beta$ while $L$ gets his payoff $U$.

\subsection{Equilibrium}

Based on E's action at the first stage, only one of the preceding cases will arise in equilibrium when ignoring mixed strategies. Given the nature of the game, we adopt subgame perfection as the appropriate equilibrium concept. We begin with solving for the equilibrium payoffs to the different players in each of the subgames described in cases (A) - (D). The appendix contains the details of the derivations of these expressions.

\subsection{Main Results}

Suppose $E$ chooses to lobby alone. In that situation (case (A)), the optimal choice of effort by $E$ is given by

$$
e_{0}=\frac{\left[\frac{R}{\psi}(1-\alpha \beta \lambda)\right]^{1 / 2}-1}{\lambda} .
$$

Suppose $E$ and $C_{1}$ decide to collectively influence the local politician, namely, case (B). Here each of the two groups provide the same per-capita effort $e$. In this subgame, the optimal

\footnotetext{
${ }^{6}$ Hence, we replace $\rho$ with $1-\rho$ in all the expressions.
} 
(common) effort level of $C_{1}$ and $E$ is given by

$$
e_{1}=\frac{\left[\frac{R \alpha}{\psi}(\theta-\beta[\lambda+(1-\lambda) \rho])\right]^{1 / 2}-1}{\lambda+(1-\lambda) \rho} .
$$

Finally, we turn to case (C), where $E$ and $C_{2}$ decide to collectively influence the local politician. In this subgame, the optimal (common) effort level of $C_{2}$ and $E$ is given by

$$
e_{2}=\frac{\left[\frac{R \alpha}{\psi}(\theta-\beta[\lambda+(1-\lambda)(1-\rho)])\right]^{1 / 2}-1}{\lambda+(1-\lambda)(1-\rho)} .
$$

LEMMA 1. $e_{1}<e_{2}$ for $\rho \in(1 / 2,1)$ and $e_{1}=e_{2}$ for $\rho=1 / 2$.

Proof. See Appendix.

This preliminary result enables us to make a comparison between E's potential lobby partners. In particular, we are able to argue that $E$ will always prefer to lobby along with the minority group over the majority one. The following observation re-iterates this point.

OBSERVATION 1. E's payoff from lobbying jointly with $C_{2}$ exceeds the one from lobbying jointly with $C_{1}$ for every $\rho \in(1 / 2,1)$.

Proof. See Appendix.

An immediate corollary of this result is the fact that E's payoff from joint lobbying is monotonically decreasing in the size of the lobbying partner.

The preceding observation is agnostic about whether $E$ prefers lobbying alone than teaming up with either of the ethnic groups. It is important to bear in mind that E's payoff from lobbying alone does not depend upon the ambient level of ethnic diversity. If it is the case that for every value of $\rho \in(1 / 2,1)$ that the elite prefer lobbying alone, then ethnic diversity would have no effect on elite capture/democratic spending at all. This issue is dealt with in the following observation.

OBSERVATION 2. There exists a unique $\hat{\rho} \in(0,1)$ such that $E$ 's payoff from lobbying jointly with $C_{2}$ exceeds the one from lobbying alone for every $\rho \in(\hat{\rho}, 1)$.

Proof. See Appendix.

We next proceed to examine $E$ 's payoff from lobbying jointly with $C_{1}$ vis-a-vis the one from lobbying alone. But before we can rank these two options, we need the following lemma.

LEMma 2. The payoff to $E$ from $E \cup C_{i}$ is increasing in $\theta$ for $i=1,2$. 
Proof. See Appendix.

Th intuition behind Lemma 2 is quite straightforward. Starting from an initial level of $\theta$, an increment (in $\theta$ ) increases the expected payoff even the effort level is kept unchanged. However, the expectation of a higher prize upon success (owing to the increment in $\theta$ ) spurs $E$ on to pick a higher effort level - the cumulative effect raises the payoff to $E$.

ObSERVATION 3. There exists a unique $\theta^{*}>1 / \alpha$ such that $E$ 's payoff from lobbying alone exceeds the one from lobbying jointly with $C_{1}$ whenever $\theta<\theta^{*}$ for every $\rho \in[1 / 2,1)$.

Proof. See Appendix.

The core intuition behind Observation 3 can be found in the logic of Lemma 2: if $\theta$ is sufficiently low then $E$ would rather seek to lobby by itself than team up with $C_{1}$. Note, however by Observation 1 , this does not preclude lobbying with $C_{2}$ which may still dominate E lobbying alone.

An immediate corollary of Observation 3 is that $\hat{\rho}>1 / 2$ - in other words, the level of ethnic diversity where $E$ would prefer switching from lobbying with $C_{2}$ to lobbying alone arrives at a point before the distinction between the sizes of the two ethnic groups disappears. This simply follows from the fact that $\pi_{E}(E)$ exceeds $\pi_{E}\left(E \cup C_{1} ; \rho=1 / 2\right)$ which in turn is identical to $\pi_{E}\left(E \cup C_{2} ; \rho=1 / 2\right)$.

Figure 1 plots the payoffs to $E$ under the three possible lobbying situations - alone (as denoted by $\pi_{E}(E)$ ), with $C_{1}$ (as denoted by $\pi_{E}\left(E \cup C_{1}\right)$ ) and with $C_{2}$ (as denoted by $\pi_{E}(E \cup$ $\left.C_{2}\right)$ ). Clearly, $\pi_{E}(E)$ is constant across all possible values of the ethnic diversity parameter $\rho$. Given the insights from Observation 1, we have $\pi_{E}\left(E \cup C_{2}\right)$ increasing in $\rho$ and $\pi_{E}\left(E \cup C_{1}\right)$ falling in $\rho$ as $\rho$ varies from $1 / 2$ to approaching unity. Observations 2 and 3 deliver a unique $\hat{\rho}$ between $1 / 2$ and unity.

It must be borne in mind that both $\pi_{E}\left(E \cup C_{1}\right)$ ) and $\pi_{E}\left(E \cup C_{1}\right)$ ) depend upon $\theta$ (recall Lemma 2) - so this figure pertains to a certain level of $\theta$. Any increase (decrease) in $\theta$ will raise (lower) both these curves while leaving $\pi_{E}(E)$ unaffected.

Based on the discussion above, it is clear that $E$ has a preference for lobbying jointly with $C_{2}$ over all other options available for a certain range of values for $\rho$ - specifically, for $\rho$ between $\hat{\rho}$ and unity. A natural question which arises in this context is the following: when does $C_{2}$ agree to lobby with $E$ rather than refuse (and either let $E$ lobby alone or with $C_{1}$ )? The following observation deals with this issue.

Observation 4. There exists $\underline{\psi}>0$ such that for any $\psi \leq \underline{\psi}, C_{2}$ will prefer to lobby jointly with $E$ than stay out whenever $\lambda$ is smaller than $\underline{\lambda}$, where $\underline{\lambda} \equiv \frac{(1-\rho)}{(\theta-\rho)}$. If $\lambda \geq \underline{\lambda}$, then $C_{2}$ will always stay out.

Proof. See Appendix. 


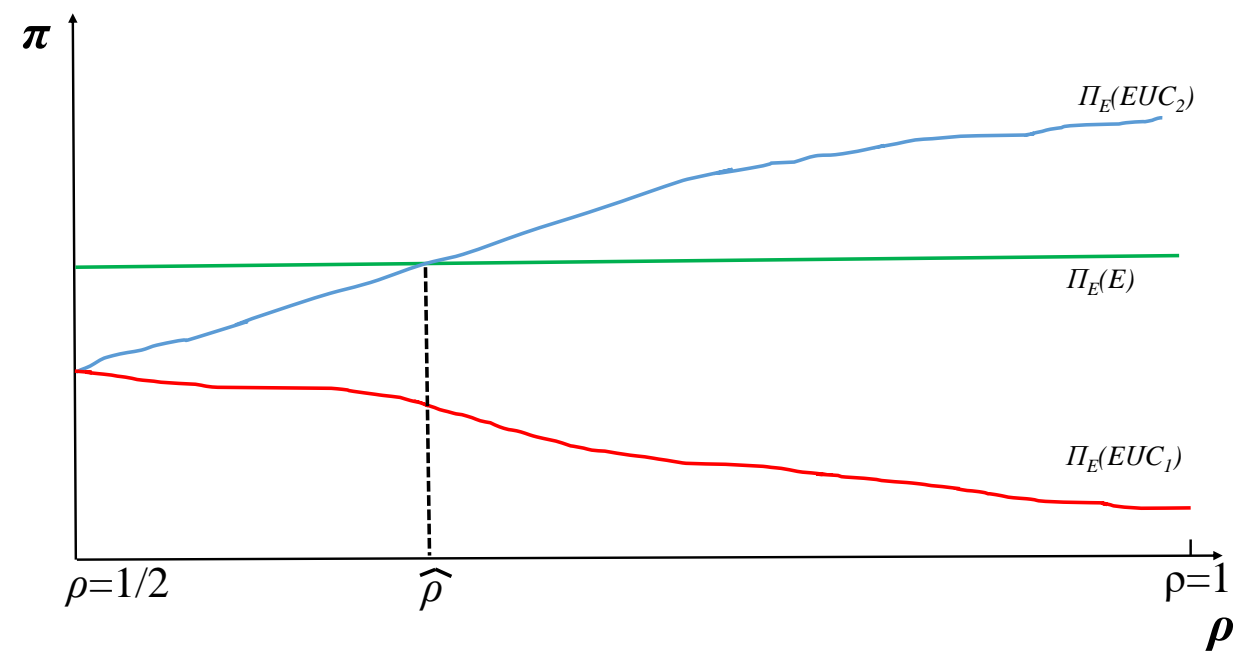

Figure 1: Payoffs to E. The dependence on ethnic diversity $(\rho)$.

It is important to note that $\underline{\lambda}$ is falling in the size of $C_{1}$. Hence, for highly homogeneous societies (i.e., $\rho \rightarrow 1$ ), $\underline{\lambda}$ approaches 0 thereby reducing the likelihood of $C_{2}$ joining $E$.

Collecting the results from the preceding observations, we have the following proposition.

Proposition 1. When $\psi \leq \underline{\psi}, \lambda<\underline{\lambda}$ and $\theta \in\left(1 / \alpha, \theta^{*}\right)$, the following is guaranteed:

(i) For $\rho \leq \hat{\rho}, E$ lobbies alone in equilibrium.

(ii) For $\rho \in(\hat{\rho}, 1)$, the equilibrium lobby group is $E \cup C_{2}$.

Proposition 1 uncovers the impact of ethnic diversity on the equilibrium lobby group. This allows us to gauge how distant the equilibrium allocation is from the social planner's namely, $R \alpha \beta$ which is the payoff to each member of the society (elite and non-elite). Increasing diversity (lowering $\rho$ ) increases the chance of pure elite capture as the equilibrium lobby shifts from being $E \cup C_{2}$ to $E$ alone. In other words, the extent of exclusion increases as one crosses $\hat{\rho}$ from the right. This, however, is not enough to claim that elite capture or greater exclusion entails on the left of $\hat{\rho}$ - one needs to account for the respective chances of success for the lobby around $\hat{\rho}$. The following observation engages with this very issue. In terms of notation, let the success probability of the lobby $E \cup C_{2}$ be denoted by $p_{2}$ and that of the lobby consisting of $E$ alone by $p_{0}$.

OBSERVATION 5. The following relations between $p_{0}$ and $p_{2}$ always hold:

(i) $p_{2}$ exceeds $p_{0}$ as $\rho \rightarrow 1$.

(ii) As $\rho$ falls, so does $\frac{p_{2}}{p_{0}}$.

Proof. See Appendix. 
As ethnic diversity increases, $\frac{p_{0}}{p_{2}}$ increases too. Hence, the success probabilities of the respective lobbies on either side of the threshold are closer to each other for values of $\rho$ close to $\hat{\rho}$ than when $\rho \rightarrow 1$.

Combining Proposition 1 and Observation 5 yields the following insight: as one focuses on a neighbourhood around the threshold $\hat{\rho}$, one observes greater exclusion for societies which are more ethnically diverse within that neighbourhood. This arises both from the size of the excluded groups and also from the fact that the success probabilities of the respective lobbies on either side of the threshold are more similar within this neighbourhood around $\hat{\rho}$. In sum, increasing ethnic diversity leads to more exclusion (or greater elite capture) when the society is somewhat ethnically diverse to begin with.

It is worth reflecting upon the fact that Proposition 1 is relevant when the marginal cost of lobbying effort $(\psi)$ is sufficiently low, the mass of the elite $(\lambda)$ is adequately small and the expropriation powers of the elite $(\theta)$ are somewhat bounded. These assumptions are not particularly demanding, especially when viewed in the context of Indonesian communities. Lobbying the local politician need not entail a high marginal effort cost. Similarly, the ability of the elite to distort the allocation in their favour could be substantial (after all $\theta$ is assumed to be higher than $1 / \alpha$ where $\alpha \in(0,1))$ but certainly is not without bounds. Finally, the elite in a community could be just a handful of individuals who because of their economic and social standing are able to dictate the order of things.

What happens if they fail to hold? If the marginal cost of effort is above the threshold, then $C_{2}$ may not find it in it's interest to lobby - thus, the equilibrium lobby group will just be $E$ alone. The issue is similar for the elite size threshold $\underline{\lambda}$. Given the definition of this threshold (i.e., $(1-\rho) /(\theta-\rho)$ ), it is more likely that this threshold is not met for highly ethnically homogeneous societies.

For $\theta$ larger than $\theta^{*}$, the possibilities are slightly richer. Clearly, for $\theta$ approaching infinity, neither $C_{1}$ nor $C_{2}$ would be willing to lobby as their respective shares $s_{1}$ and $s_{2}$ would have been driven to zero - so again the lobby group is simply $E$. However, there is a range for $\theta$ beyond $\theta^{*}$ where $C_{1}$ may be willing to join (while $C_{2}$ refuses). To be sure, whether $E$ would prefer teaming up with $C_{1}$ over going ahead alone is indeterminate. But it may be possible that for certain configurations of the parameters, the equilibrium lobby is indeed $E \cup C_{1}$. Figure 2 depicts such a possibility. Here, for $\rho \in[1 / 2, \hat{\rho})$ the equilibrium lobby group is $E \cup C_{1}$ as $C_{2}$ prefers staying out of the lobby. For $\rho \in[\hat{\rho}, 1), E$ lobbies alone. Comparing this situation with Proposition 1, brings out the differences most starkly. In this situation, the extent of elite capture/exclusion actually falls with increases in ethnic diversity.

The preceding discussion makes it clear that if the conditions for Proposition 1 are not met then the predictions of the model would be substantially different and in some cases be the polar opposite. ${ }^{7}$

\footnotetext{
${ }^{7}$ This is something one could test empirically and the results could in a sense validate (or invalidate) the assumptions listed for Proposition 1.
} 


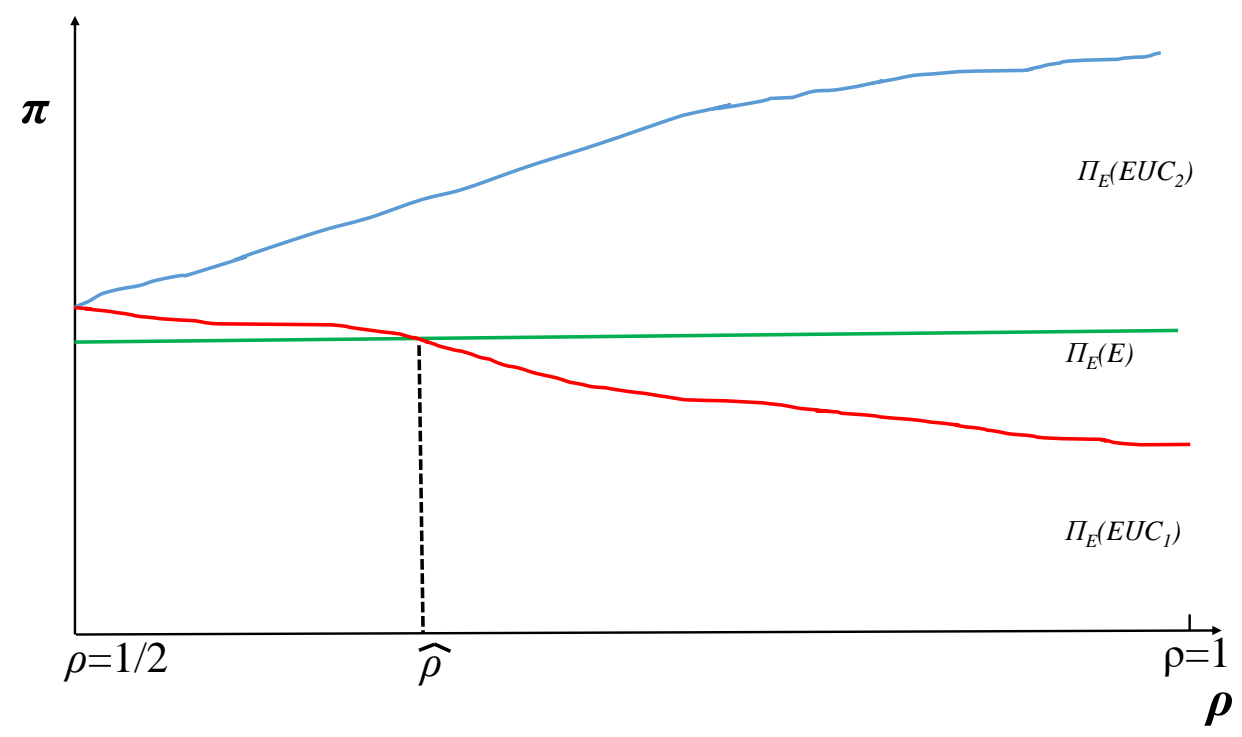

Figure 2: Payoffs to E. Variation with $\theta$.

Given Proposition 1, one is tempted to ask if the level of ethnic taste differences or coordination costs - captured by $\beta$ - affect this relationship between ethnic diversity and elite capture. This is the subject of the following observation.

ObSERVATIOn 6. Any increase in the ethnic taste differences or coordination costs (i.e., any decrease in $\beta$ ) leads to an unambiguous rise in lobbying efforts for every $\rho \in[1 / 2,1)$.

Proof. See Appendix.

The logic behind Observation 6 is easy to grasp. As the default option - i.e., $R \alpha \beta-$ becomes less attractive, each of the potential lobby groups respond by increasing their effort levels so as to avoid the default option. Note, Observation 6 does not affect the result in Proposition 1 in any significant qualitative way although there is clearly a quantitative impact (all the payoff curves for $E$ in Figure 1 respond to shifts in $\beta$ ). In particular, one may claim - by Observation 6 - that for lower values of $\beta$ there will be a higher chance of success for the lobby and hence the probability of exclusion (of the non-lobbying group(s)) increases for all feasible values of $\rho$. Hence, the result in Proposition 1 is quantitatively amplified as one considers the scenario of high coordination costs. This is summarised in the following proposition.

Proposition 2. In societies with high coordination costs across ethnic groups (i.e., low $\beta$ ), the extent of elite capture increases with diversity (i.e., with falling $\rho$ ) provided that the conditions for Proposition 1 are met.

These nuanced differences, that we uncover, in the effects of ethnic diversity and taste diversity/coordination costs - independently and collectively — on the dynamics of local 
public spending seem amenable to empirical testing. In what follows, we describe how we proceed to test these theoretical predictions in the context of local governance in Indonesia.

\section{$3 \quad$ Empirical Analysis}

The theory, although simple, provides a rich set of testable predictions. We focus on the following ones:

(i) Ethnic diversity leads to more distortion in local public spending - hence, there is a movement away from what non-elites want.

(ii) The degree of elite capture is greater in societies where taste diversity/coordination costs across ethnic groups is higher thus strengthening the effect of ethnic diversity.

(iii) The effects listed in (i) and (ii) are salient in societies which exhibit some ethnic diversity (not nearly homogeneous ethnically).

The logic of (iii) relies on the fact that for nearly homogeneous societies two possibilities are particularly strong: (a) the threshold value of diversity $(\hat{\rho})$ may lie outside the range of such societies, and so the switch in lobby identity does not happen and (b) as the elite size threshold $(\underline{\lambda})$ gets very tight for such societies, it may happen that the equilibrium lobby for these societies is just $E$. Notice, in the case of either (a) or (b) one will not observe the patterns listed in (i) and (ii).

In the empirical exercise, we examine various items of local public expenditure and in particular, look at developmental spending which clearly is valued by the non-elites. Combining with this data on ethnic diversity at the level of the community, we are able to check the prediction in (i).

For (ii), we exploit a special institutional feature of Indonesian communities. In certain communities, historically there has been "consensus building" on collective activities which follows from the community's adherence to Adat laws. These laws promote an ethic of mutual cooperation in the community. We argue, in greater detail in Section 3.4, that such active interaction across the ethnic groups reduces coordination costs/prejudiced-based differences across the same within the community in question. In light of this community-level feature, we check if the link between ethnic diversity and local public spending is affected by whether the community adheres to Adat laws or not. To be specific, a community which is ethnically diverse and does not adhere to these Adat norms will be subject to greater capture by the elite lobby and hence implement policies less favourable to the masses.

All of these predictions can only have salience if the local politician actually has any influence on community-level spending. Hence, we examine this in the context of fiscal decentralisation in Indonesia which came into force at the turn of the century. 


\subsection{Data}

Our analysis is based on the community level data obtained from 1997 and 2007 Indonesian Family Life Survey (IFLS) from 312 rural and urban communities, drawn from 36 districts lying in 13 provinces including Jakarta, Bali, Java (central, east and south), Sumatra (north, west and south), Lampung, West Nusa Tenggara and south Kalimantan. Although IFLS data are available for the years 1993, 1998 and 2000 as well, information on local politics could be found only in the 1997 and 2007 surveys, thus explaining our choice of the sample years.

This is a particularly rich data set that provides community level information on a whole range of demographic characteristics and access to public goods, local governance and its public finances, citizens' participation in planning and implementation of local development projects, as well as a range of public utilities, infrastructure and transport, health and education facilities (see Frankenberg and Thomas (2000) and Strauss et al. (2009) for study design and overview of the data set).

\subsection{Background}

\begin{tabular}{lrrrr}
\hline & \multicolumn{2}{c}{$\underline{\mathbf{9 9 7}}$} & \multicolumn{2}{c}{$\underline{\mathbf{2 0 0 7}}$} \\
& Rural & Urban & Rural & urban \\
\hline Consensus & 38 & 53 & 15 & 18 \\
Voting & 64 & 50 & 100 & 78 \\
Oligarchy & 18 & 89 & 5 & 96 \\
\hline Total & 120 & 192 & 120 & 192 \\
\hline \hline
\end{tabular}

Table 1: Different methods of selection of community leaders. Notes. 'Consensus' $=1$ if the community leader is selected by consensus building through meetings; 'Voting' $=1$ if the community leader is elected by voting; 'Oligarchy' $=1$ if the community leader is selected by few elites.

With the introduction of the '1979 village law', village affairs were brought under the supervision and close control of higher authorities. While the law stated that the village had "the right to manage its own affairs", it immediately noted that this "does not mean autonomy" (General Clarification, section 7). The village was nothing more and nothing less than "the lowest level of the government structure directly under the sub-district chairman". Since 1979, the head of villages classified as 'desa' has been elected in village-level elections held every 8 years, while the heads of 'kelurahan' villages (urban/city) were appointed by upper levels of administration. These have been the de jure selection rules of community leaders though in practice the process of selection of the community leader may vary (see Table 1). In short, Indonesia has been culturally and politically decentralised even though local 
leader selections may have been controlled by the central regime under Suharto; however, the nation was under the unambiguously tight grips of central fiscal control until 2001.

Fiscal decentralisation in post-Suharto Indonesia was largely an exogenous event for the communities, which has its roots in Law 22/99 and Law 25/99 enacted in January 2001. It gave local communities more autonomy in raising local revenues while enforcing strict budgetary cuts on the central leadership to supply development grants to these communities. It also granted administrative authority to local governments to hire staff and conduct local government affairs with a minimum intervention of the central government; local community governments were made responsible to the district government who provided the bulk of their funds after FD; in other words the centre of power moved from the central government in Jakarta to the district governments located in district head-quarters after FD. We study these local communities at 1997 and at 2007, two points in time separated by the introduction of FD in 2001.

\subsection{Measures of local development}

The composition of public spending and public goods has become the key instrument for policies for economic development (IMF and World Bank 2003). In recent years, development assistance to heavily indebted poor countries has been made conditional on increase on certain categories of public spending that are thought to be pro-poor. In particular, components of public spending aimed at reducing poverty levels focuses on education, health, agriculture, safety nets, infrastructure, rural development and others (IMF and World Bank 2003). This practice has its roots in the works of Aschauer (1989), Barro (1991), Easterly and Rebelo (1993), Devarajan et al. (1996). Aschauer (1989) argued that investment in core infrastructure like streets, railways, airports has the most explanatory power for private sector productivity in the United States. Along similar lines Easterly and Rebelo (1993) suggested that public investment in infrastructure boosts economic growth. Barro (1991) further argued that productive spending on education (which develops human capital) and defence (which protects property rights) are growth enhancing. In this respect, a distinction is often made between social and physical infrastructural goods. While investment in physical (e.g., transport and communications) infrastructure will facilitate production of both goods and services, investment in health and education will contribute to healthy and educated workers, and thereby improve labour productivity.

Fiscal decentralisation of 2001 had offered more autonomy in local spending (and not in revenue collection) and the delivery of public services including health, education and physical infrastructure (Brodjonegoro, 2001). IFLS data provides information on the spending allocation of the local community government in both 1997 and 2007 rounds. Total spending has the following components: (i) development spending refers to spending on new social (e.g., local schools and health centres) and physical (e.g., roads and transport) infrastruc- 
ture as well as maintenance of existing infrastructure; (ii) non-development spending includes spending on staff salary, office maintenance, official trips and contingencies; (iii) some underdeveloped communities also receive grants for various developmental programs, e.g., IDT for under-developed communities.

The selection of communities for the Inpres Desa Terttingal (IDT) program is made by the National Development Planning Agency (BAPPENAS) and the Ministry of Home Affairs (MoHA) and it is based on the PODES socioeconomic survey by the Central Bureau of Statistics. The 1994 selection considered three basic indicators: village facilities and potential, housing and the environment and population characteristics. The selection criteria however had some flaws for identifying consumption levels; for instance, too much weight was given to infrastructure deficiencies that do not always reflect lowest consumption levels-and thus the selection for the 1995 program gave more prominence to expenditure levels. Also, the number of households in the community determined how often these communities would be selected for IDT funds. Under IDT, the government, by virtue of presidential instructions, provided selected poor communities (or villages) with lump-sum grants designated for small business loans. These selected villages were then instructed to choose relatively poor households that would be eligible for IDT loans based on village-level meetings. These were facilitated by the village head and a local government agency called Lembaga Ketahanan Masyarakat Desa (LKMD, Village Community Resilience Board). About $40 \%$ of the communities have been selected for the anti-poverty programme IDT in our sample.

Accordingly, our key index of local development is the natural logarithm of annual development spending (labelled as devexp) for each community. We also analyse a similar measure which include funds from IDT. We also check the robustness of these estimates by considering the natural logarithm of communitys annual spending on social infrastructure (labelled as socexp) and also that on physical infrastructure (labelled as infraexp). For indicators of public spending which are not development related, we utilise the information on salary and administrative expenses of the local officials. ${ }^{8}$

\subsection{Community Co-ordination and Adherence to Adat norms}

Adat law was recognised by the colonial administration in the Dutch Indies as part of a dual legal system in which natives were subject to 'their own religious laws, institutions and customs so far as they were not in conflict with generally recognized principles of equity and justice ...' (Fasseur 2007). In an effort to promote national unity, the post-colonial Suharto regime took a more heavy-handed approach, and 'no political rights were allowed to follow from cultural difference or ethnic identity' (Davidson and Henley, 2007: Chapter 1). Over time, the new system of local governance introduced by the Suharto regime, including administrative bodies at the district and community level, significantly undermined the

\footnotetext{
${ }^{8}$ More on these different measures of spending later.
} 
authority of adat leaders and their ability to enforce adat rules (Kato 1988). Nevertheless, adat law remained salient and relevant, especially to rural life in Indonesia during the Suharto regime.

\begin{tabular}{lcccc}
\hline \hline & 1997 (\% of total communities) & 2007 (\% of total communities) \\
\hline & $\begin{array}{l}\text { Rural } \\
\text { (desa) }\end{array}$ & $\begin{array}{c}\text { Urban } \\
\text { (kelurahan) }\end{array}$ & $\begin{array}{c}\text { Rural } \\
\text { (desa) }\end{array}$ & $\begin{array}{c}\text { Urban } \\
\text { (kelurahan) }\end{array}$ \\
\hline Adat laws are never broken & 38.41 & 24.81 & 28.69 & 21.63 \\
Adat laws are sometimes broken & 40.58 & 51.13 & 35.25 & 23.56 \\
Adat laws are frequently broken & 1.45 & 3.76 & 9.84 & 20.67 \\
Only a few understand Adat laws & 19.57 & 19.55 & 26.23 & 34.13 \\
\hline \hline
\end{tabular}

Table 2: Adherence to Adat laws. Sources and Notes. Percentages are based on responses to questions in the community questionnaire in IFLS2 and IFLS4 regarding the extent to which community members follow adat laws.

Based on the knowledge and information of a local expert, the Indonesian Family Life Surveys (IFLS) classified all communities in terms of their 'adherence to adat laws'. The IFLS data place each community into one of four possible categories: (i) traditional laws are almost never broken; (ii) traditional laws are sometimes broken; (iii) traditional laws are frequently broken and (iv) only a few people understand traditional laws.

In nearly $80 \%$ of rural communities and $75 \%$ of urban communities, adat laws were reported to be 'feared' and sometimes or 'almost never broken' in the 1997 survey. Using the same dataset, Bandiera and Levy (2011) find a strong correlation (73\%) between community governance according to adat law and current practice. In the following years, Indonesia witnessed major economic and political changes, including the East Asian Financial crisis, the end of the Suharto regime and the beginning of the process of fiscal decentralisation. By 2007, adherence to adat laws appear to have declined significantly with $61 \%$ of rural communities and $45 \%$ of urban communities reporting that they were 'feared' and 'sometimes broken' or 'almost never broken'.

We classify a community as an adat community if adat laws are 'almost never broken'; it is a non-adat community otherwise. Table 2 summarises the adherence to adat laws in rural and urban communities in 1997 and 2007. Overall, a smaller proportion of sample communities adhered strictly to adat law in 2007 than in 1997.

Adat rules generally prescribe how each community member should contribute to collective activities as well as the punishment for falling short of these prescriptions. Therefore, we argue that communities where adat rules are generally ignored or forgotten, cooperation in traditional collective activities are also weak. In most of the Adat communities, there is a strong presence of presence of mutual co-operation groups in both the 1997 and 2007 IFLS rounds. Furthermore, Table 4 in Pal and Wahhaj (2017) demonstrates how individuals who 
break the adat rules of their community can face significant penalties, including the payment of fines, ostracism and even, in some cases, expulsion from the community. As expected, the penalties are more severe in communities which practise stronger adherence to adat laws.

\subsection{Ethnic diversity}

We observe the size of the top three ethnic groups in each sample community which we use to construct two alternative indices of ethnic diversity which are commonly used in the literature. It is worth reiterating that the top three ethnic groups in any community basically form all of it. Our first measure is Frac which is defined as follows: Frac $=1-\sum p_{i}^{2}$ where $p_{i}$ is the population share of the $i$-th group, for $i=1,2,3$. In this case, the larger the sum of squares of the three population shares, the smaller will be the extent of ethnic diversity measure Frac.

We also generate an alternative index of ethnic diversity labelled Frac1, which is measured by the inverse of the largest ethnic group. The larger the size of the largest ethnic group, the lower is the extent of ethnic diversity measure Frac1 and vice versa.

It is important to re-iterate that the Adat customs are embraced by the community as a whole or not; and this is quite unrelated to the ethnic divisions in the community. Hence, Adat norms may help build social co-operation even in ethnically diverse society using a carrot-andstick approach: (i) the presence of mutual co-operation groups for security, health, education, food security, construction and infrastructure, and assistance to community members; and (ii) the use of punishment/ostracisation to discipline in the case of transgressions.

\subsection{Empirical strategy}

We aim to assess the effect of ethnic diversity on local public spending following fiscal decentralisation and how the relation is conditioned by the community's adherence (or not) to Adat laws (our measure of local institutions). This motivates the following empirical specification for community $i$ in year $t$ :

$$
\begin{aligned}
Y_{i t}= & \beta_{0}+\beta_{1} F_{t}+\beta_{2} \text { NonAdat }_{i}+\beta_{3} \text { Eth.Div }_{\cdot i}+\beta_{4} \text { NonAdat }_{i} * \text { Fo }_{t}+\beta_{5} \text { Eth.Div }_{\cdot i} * F D_{t} \\
& +\beta_{6} \text { Eth.Div }_{i} * \text { NonAdat }_{i} * F D_{t}+\beta_{7} \text { Eth.Div }_{i} * \text { NonAdat }_{i}+\gamma \mathbf{X}_{\mathbf{i}}+D_{i}+u_{i t}
\end{aligned}
$$

The dependent variable $Y_{i t}$ represents a set of local public spending variables in the community - indexed by $i$ - including development spending (devexp) and IDT, spending on social (socexp), on physical infrastructure (infraexp) at period $t$ where $t \in\{1997,2007\}$. Note that spending on social and physical infrastructure are two components of total devel- 
opment spending in a community in a year. The rest of the total community spending is spent on wages and salaries of community staff, their travels and other administrative items. We utilise the last set of variables too.

The spending items under the "development spending" head are likely to generate investment in essential public goods, both physical infrastructure like roads and transport and social infrastructure like health and education facilities, which are likely to boost local development. Here, our flagship dependent variable is the (natural log of) total development spending in the community. ${ }^{9}$ We also report results with the share of development spending (at the community level) — denoted by shdev — as an additional metric of general welfare spending.

The variable $F D_{t}$ is essentially a dummy variable which takes a value of 1 for year 2007 and 0 for 1997. The $D_{i}$ variables represents the district dummies so that the comparison is across communities — within a district — pre and post fiscal decentralisation.

In order to capture the variation in inter-ethnic coordination costs, we utilise whether the community had a stable adherence to traditional adat laws or not. In particular, we construct a binary variable Adat that takes a value 1 if a community strictly adhered to adat laws in both the sample years 1997 and 2007; it is 0 for others. It follows from Table 2 that a community's adherence to adat laws declined between 1997 and 2007, which reflects the strategic nature of this choice by sample communities. In order to avoid this aspect of strategic choice, we utilise this stricter definition of Adat so as to ensure that there has been no change in adherence to adat laws in these communities. The variable Non - Adat is basically $1-$ Adat and hence reflects those communities where adherence to Adat norms has been lax/non-existent in either of the two periods.

Traditional institutions like adat laws have, historically, played an important role in community life in Indonesia, up to and during the colonial period. It follows from our earlier discussion that communities where adherence to adat laws was strong, community members were expected to participate in, and could expect to benefit from, a range of collective activities and this is the traditional practice. A community's adherence to adat laws is determined by the age-old traditions rather than by current community governance structure, thus making Adat (equivalently, Non-Adat) exogenous to the local public spending process.

Given that fiscal decentralisation offered more autonomy to these communities, we interact the Non - Adat variable with the $F D_{t}$ dummy. This is guided by our theoretical model, which relies on the premise that fiscal decentralisation raises the stakes for the elite to lobby. The precise distortion arising out of lobbying as we argue in the theoretical model, depends crucially on the extent of coordination costs across the various groups within a community, an issue closely linked to whether or not the community ascribes to Adat laws.

We use two different measures of ethnic diversity. The flagship one is the standard fraction-

\footnotetext{
${ }^{9}$ We use $\log (1+$ Devexp $)$ in order to deal with cases where there has been no spending under the development head.
} 
alisation type of measure which we denote by Frac. We also employ an alternative definition of diversity, which we call Frac1, which is simply the inverse of the size of the largest ethnic group (both measures have been defined precisely earlier).

The set of other control variables $\mathbf{X}_{\mathbf{i}}$ include a number of community-level variables used in the analysis. These include variables like whether the head has completed High School (dummy variable), head lives in the community (dummy variable), community population, community area (in hectares), Urban/Rural community (dummy variable), distance from the district headquarters (in miles) and if Islam is the dominant religion (dummy variable). Table 3 summarises the summary statistics of all the relevant variables. It is useful to bear in mind that nearly three-fourths of the communities in our sample do not follow Adat norms in a strict sense. Also, both measures of ethnic diversity indicate that while the communities in Indonesia are fairly ethnically diverse there is significant heterogeneity across them. In particular, nearly half of the sample communities are very homogeneous in the sense that the largest ethnic group is at least $91 \%$ of the community's population. The key coefficient of interest is $\beta_{6}$ - the one on the triple interaction term NonAdat*Eth.Div.*FD . This captures the partial effect on the various measures of community-level spending of a community's being ethnically diverse and having high coordination costs — within a district - in the post-decentralisation period. By hypotheses (i) and (ii), we expect $\beta_{6}$ to be negative.

Note, the identification strategy relies on the following factors. First, we argue that the key explanatory variables are exogenous: (a) fiscal decentralisation was imposed by the central government and as such was beyond the influence of local communities in Indonesia. (b) The measure of ethnic diversity is stable (over time) in our sample communities and is therefore unaffected by the outcome variables. (c) We consider a communitys stable adherence to adat/non-adat rules over time, thus mitigating concerns regarding reverse causation.

There may still remain some unobservable factors that may influence these key explanatory variables and if correlated with the random error term, could bias our estimates. In order to reduce this potential omitted variable bias, we include a rich set of community-level time invariant factors as control variables.

Fragmented geography and urbanisation could be important candidates for ethnic diversity (Ahlerup and Olsson (2007), Michalopoulos (2012)) which justify the inclusion of two binary variables, namely, if it is an urban community and also if the community has access to sea. While we do not have information on land quality, but inclusion of community population and geographic size of the community would reflect population density which could be considered to be a proxy for land quality especially in rural communities. We also control for distance of the community from district head quarter to account for the closeness of the community to the district head quarter. The latter became particularly important after fiscal decentralisation as the centre of power moved from Jakarta to the district head quarters, as district authorities became responsible for disbursement of central funds and also for monitoring the community's progress. 


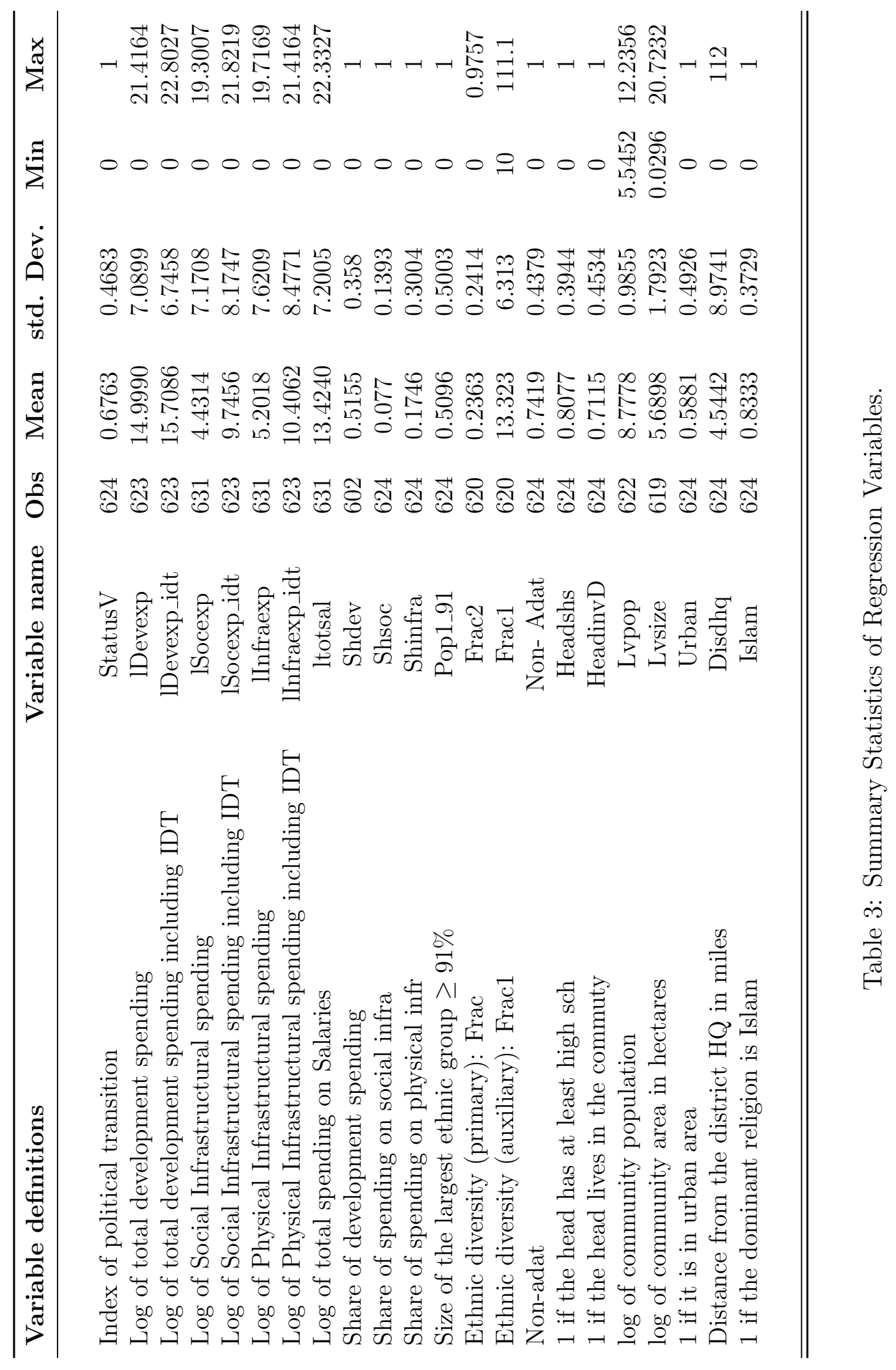


Finally, all regressions include district fixed effects (the set of $D_{i}$ dummies), further reducing heterogeneity across communities located in different districts. In other words, we examine the variation in different accounts of development and non-development spending across communities with different levels of adherence to traditional law and ethnic diversity within the same district before and after fiscal decentralisation.

\subsection{Results}

Our baseline results are collected in Table 4. In each column in this table, the dependent variable is the (log of) total development spending in the community. For the results reported in the first two columns, the sample is restricted to communities which are Non-Adat - so they have not strictly adhered to Adat customs in both survey rounds (1997 and 2007).

The idea is that these are communities where coordination costs across ethnic groups is higher than in the remaining communities. So predictions (i) and (ii) listed under Section 3 are being put to a test here. We check for whether more ethnically diverse communities had different levels of development spending in the post-decentralisation period in communities marked by a poorer record of inter-community cooperation. In other words, is the coefficient Frac $*$ FD statistically significant when the universe is that of Non-Adat communities?

Prediction (iii) under Section 3 states that the effects are more salient in societies which exhibit some ethnic diversity (not nearly homogeneous ethnically). This motivates the removal of ethnically homogeneous communities; hence, column (1) restricts the sample to those Non-Adat communities which are not completely ethnically homogeneous. Column (2) takes this idea even further by restricting the sample to those Non-Adat communities where the largest ethnic group constitutes less than $91 \%$ of the population, hence Pop $1<91$. We pick this $91 \%$ cutoff as nearly half of the sample communities are very homogeneous in the sense that the largest ethnic group is at least $91 \%$ of the community's population (see Table 3 above for the variable Pop1_91).

By predictions (i)-(iii), we expect the coefficient on Frac*FD to be negative and statistically significant in column (2) and perhaps so in column (1) as the effect is theoretically predicted to be more robust in a set of communities with some level of ethnic diversity.

This is precisely what we find. The coefficient on $F r a c * F D$ is not statistically significant in column (1) but becomes negative and statistically significant in column (2). This suggests that more ethnically diverse communities had lower levels of development spending in the post-decentralisation period when we focus on communities with higher inter-ethnic coordination costs (i.e., Non-Adat). Notice, we always employ district fixed effects; hence, the comparison is across communities within a district. Additionally, we control for a rich array of community-level characteristics given that we are unable to use community fixed effects.

In the remaining columns of Table 4, we test for this in a more comprehensive manner by 


\begin{tabular}{|c|c|c|c|c|}
\hline VARIABLES & $\begin{array}{c}(1) \\
\text { Pop } 1<100\end{array}$ & $\begin{array}{c}(2) \\
\text { Pop } 1<91\end{array}$ & $\begin{array}{c}(3) \\
\text { Pop } 1<100\end{array}$ & $\begin{array}{c}(4) \\
\text { Pop } 1<91\end{array}$ \\
\hline & Non-Adat only & $\underline{\text { Non-Adat only }}$ & & \\
\hline Non-Adat & & & $\begin{array}{r}-3.1942 \\
(2.357)\end{array}$ & $\begin{array}{c}-19.1464 * * * \\
(3.135)\end{array}$ \\
\hline Frac & $\begin{array}{c}-4.9197^{* *} \\
(2.369)\end{array}$ & $\begin{array}{l}2.4586 \\
(4.365)\end{array}$ & $\begin{array}{c}-20.2225^{* *} \\
(8.037)\end{array}$ & $\begin{array}{c}-52.5698^{* * *} \\
(7.250)\end{array}$ \\
\hline FD & $\begin{array}{c}4.2454^{* * *} \\
(1.179)\end{array}$ & $\begin{array}{c}9.5001^{* * * *} \\
(2.200)\end{array}$ & $\begin{array}{l}1.2618 \\
(3.148)\end{array}$ & $\begin{array}{c}-23.1998^{* * *} \\
(7.056)\end{array}$ \\
\hline Non-Adat*Frac & & & $\begin{array}{c}15.2051^{*} \\
(8.168)\end{array}$ & $\begin{array}{c}54.6076^{* * *} \\
(8.186)\end{array}$ \\
\hline Non-Adat*FD & & & $\begin{array}{l}2.9850 \\
(2.973)\end{array}$ & $\begin{array}{c}32.4904^{* * *} \\
(7.925)\end{array}$ \\
\hline Frac*FD & $\begin{array}{l}0.5242 \\
(2.471)\end{array}$ & $\begin{array}{c}-9.8788^{* *} \\
(4.431)\end{array}$ & $\begin{array}{l}15.5029 \\
(9.477)\end{array}$ & $\begin{array}{c}76.5060^{* * *} \\
(15.758)\end{array}$ \\
\hline Non-Adat*FD*Frac & & & $\begin{array}{c}-15.0490 \\
(9.677)\end{array}$ & $\begin{array}{c}-85.9700^{* * *} \\
(16.569)\end{array}$ \\
\hline Constant & $\begin{array}{c}8.9196^{* *} \\
(3.846)\end{array}$ & $\begin{array}{l}0.5410 \\
(4.511)\end{array}$ & $\begin{array}{c}11.2285^{* *} \\
(5.354)\end{array}$ & $\begin{array}{c}20.0649^{* * *} \\
(4.755)\end{array}$ \\
\hline Other controls & Yes & Yes & Yes & Yes \\
\hline District FE & Yes & Yes & Yes & Yes \\
\hline Observations & 413 & 288 & 436 & 300 \\
\hline R-squared & 0.218 & 0.256 & 0.227 & 0.265 \\
\hline
\end{tabular}

Table 4: Diversity and local development spending. Notes. The dependent variable in columns (1) through (4) is the log of Development expenditure in the community, i.e., lDevexp. Local institution is proxied by Non-adat in all the columns. In the first two columns, we restrict the sample to those communities which do not strictly adhere to Adat norms in both rounds (i.e., 1997 and 2007), hence NonAdat communities. In the remaining two columns, we utilise both Adat and Non - Adat communities. In columns (1) and (3) the sample is restricted to those communities which are not entirely ethnically homogeneous, hence Pop $1<100$; and in columns (2) and (4) the sample is restricted to those communities where the largest ethnic group constitutes less than $91 \%$ of the population, hence Pop $1<91$. Other controls: Head has completed High School (dummy variable), Head lives in the community (dummy variable), community population, community area (in hectares), Urban/Rural community (dummy variable), distance from the district headquarters (in miles) and if Islam is the dominant religion (dummy variable). Robust standard errors clustered at the district level in parentheses. *, **, and *** indicate significance at the $10 \%$, $5 \%$, and $1 \%$ level, respectively. 
pooling together both sets of communities - Adat-adhering and the rest. Column (3) is a direct analogue of column (1) but now including the Adat-adhering communities as well. The estimation equation is the one specified above in Section 3.6. So now, the coefficient of interest is one on the triple-interaction term Non-Adat*Frac ${ }^{*} F D$. By the logic of predictions (i)-(iii), we expect this coefficient to be negative and statistically significant in column (4) and perhaps so in column (3). Again, the results are in line with these expectations. The coefficient on Non-Adat $^{*} F r a c^{*} F D$ is not statistically significant in column (3) but becomes negative and statistically significant in column (4). This is suggestive of the fact that ethnically diverse communities which do not follow an ethic of mutual cooperation (i.e., Adat laws) tend to have lower development spending in the post-decentralisation period. Table 9 in the Appendix is an exact counterpart to Table 4 where in the former case the outcome variable is the (log of) total development spending including that from the IDT programme in the community.

In the remainder of the analysis, we will repeatedly check for such patterns using this pooled sample of Adat-adhering and non-adhering communities for different variables pertaining to local public spending.

\subsubsection{Spending in levels and as shares}

The implications of the results in Table 4 are probed further here. In particular, we aim to explore the heterogeneity in the coefficient on the triple-interaction term Non-Adat ${ }^{*} F r a c^{*} F D$ as we examine different samples of communities. To that end, we distinguish between the set of communities which are ethnically diverse as opposed to ones which are nearly ethnically homogeneous; this is in the spirit of prediction (iii).

Table 5 contains some such results. Here, we contrast the findings across the two sets of communities - ethnically diverse and not - in alternating columns. In the odd-numbered columns, the sample is restricted to fairly homogeneous communities, i.e., where the size of the largest ethnic group constitutes is at least $91 \%$ of the population. In the evennumbered columns, the sample is restricted to those communities where the largest ethnic group constitutes less than $91 \%$ of the population.

In the first two columns, the dependent variable is the log of development spending and in columns (3) and (4) it is the log of development spending including IDT. As can be seen from columns (1)-(4), the coefficient on the triple-interaction term Non-Adat*Frac* $F D$ is statistically significant when one considers the set of communities which are more ethnically diverse, i.e., when Pop $1<91$. Moreover, the coefficient is negative re-enforcing the main idea from Table $4 .^{10}$

\footnotetext{
${ }^{10}$ For the sake of the structure of Table 5, column (2) here is reproduced from Table 4.
} 


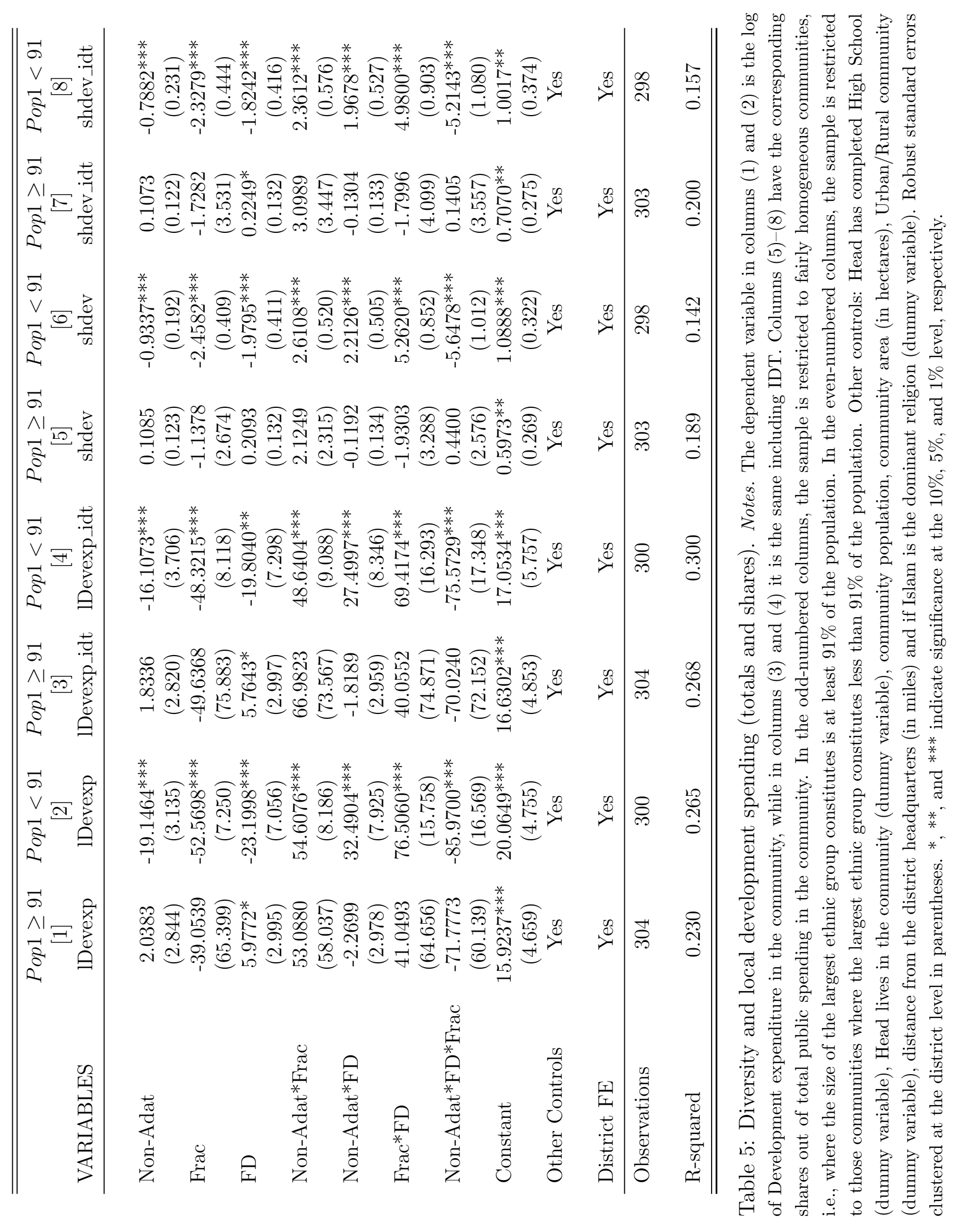


Each of the columns (5)-(8) in Table 5 have, as the dependent variable, the share of development spending out of the total public spending in the community. In columns (5) and (6) it is share of development spending (out of the total public spending at the community level) and in columns (7) and (8) it is the share of development spending when including the IDT programme. Looking at the share in apposition with the level is interesting for the following reason. It provides a sense of whether there was a more (or less) than proportional change in response to any potential changes in the overall budget at the community level. This is important as the remaining share is clearly non-development spending which is largely wages and salaries of community staff, their travels and other administrative items. We posit that these latter items are something valued by the elite - at least, more than what the non-elite do as they are typically not the direct beneficiaries - and hence looking at how the share of development spending (and thereby, non-development spending) responds is quite illuminating.

As can be observed from the columns (5)-(8) in Table 5, the coefficient on the tripleinteraction term Non-Adat $^{*} F r a c^{*} F D$ is statistically significant when one considers the set of communities which are more ethnically diverse, i.e., when $P o p 1<91$. Thus, apart from there being a negative association with the level of development spending there exists one when considering the share of development spending too. The latter results are suggestive of the idea that in the post-decentralisation period, there is also a relative movement away from what the non-elite want (i.e., development spending) in addition to there being an absolute one in communities which do not strictly adhere to Adat laws and are ethnically diverse.

These results are robust to using an alternative measure of ethnic diversity. Table 10 in the Appendix replicates the findings in Table 5 using our second measure of ethnic diversity, namely, Frac1.

\subsubsection{Components of Development Spending}

We next proceed to unpick the effects on the two components of development spending in the community - namely, physical infrastructure spending and social infrastructure spending.

As mentioned earlier, the former comprises spending on roads, communications and connectivity while the latter concerns spending on healthcare and education. While these two forms of infrastructural spending are quite distinct in terms of their aims and objectives, there is little reason a priori to presume that the non-elites would prefer one set more than the other. To be sure, one could reasonably argue that the elite care about these aspects too but it is well-known that they have other possibilities of fulfilling their needs (e.g., private schooling and health facilities) which the poor have no recourse to. In that sense, it is plausible to claim that these types of spending are more valued by the non-elite sections of society.

In Table 6, we report some results where the outcome variable is one or the other type of infrastructure spending at the community level. 


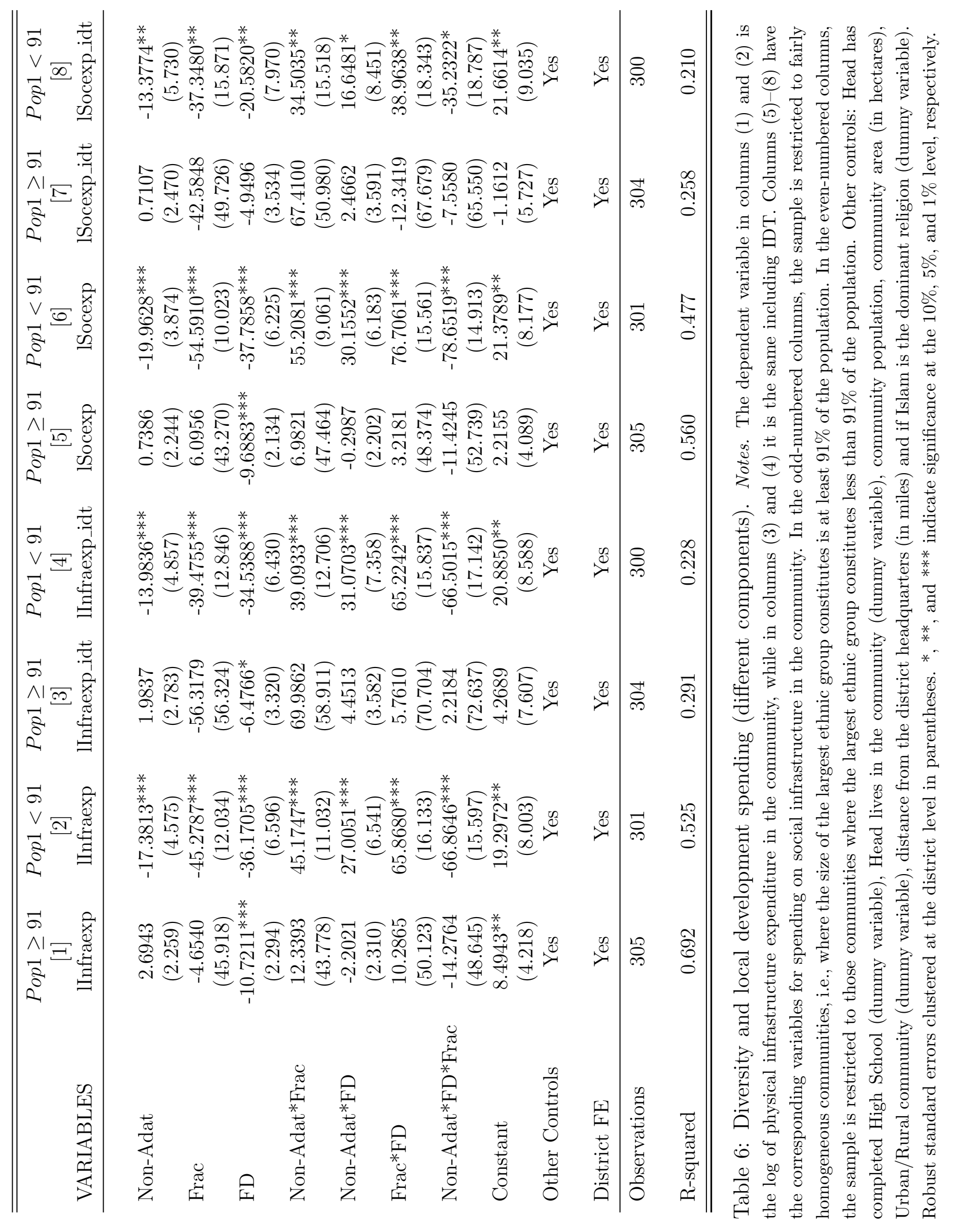


Specifically, in columns (1) and (2), the dependent variable is the log of physical infrastructure spending in the community while in columns (3) and (4) the dependent variable is similar but also accounting for the IDT programme. Columns (5)-(8) pertain to social infrastructure spending with columns (5) and (6) having the log of social infrastructure spending in the community as the dependent variable while columns (7) and (8) have use their counterparts which account for the IDT programme. Like in Table 5, in the odd-numbered columns, the sample is restricted to fairly homogeneous communities, i.e., where the size of the largest ethnic group constitutes is at least $91 \%$ of the population. In the even-numbered columns, the sample is restricted to those communities where the largest ethnic group constitutes less than $91 \%$ of the population.

The pattern which emerges is broadly the same as documented for total development spending in Table 5.

In the sample of communities where the largest ethnic group constitutes less than $91 \%$ of the population, the coefficient on the triple-interaction term Non-Adat*Frac* ${ }^{*} F D$ is negative and statistically significant for both categories of infrastructure spending. In the case of physical infrastructure spending, the magnitude of the coefficient is similar when comparing across the with and without IDT columns. This is, however, not the case for social infrastructure spending where the coefficient is much reduced in size and somewhat in significance in the case of spending which accounts for IDT. While this asymmetry is interesting in its own right, we do not dwell upon it as our theory is agnostic about this.

These results are robust to using an alternative measure of ethnic diversity. Table 11 in the Appendix replicates the findings in Table 6 using our second measure of ethnic diversity, namely, Frac1.

\subsubsection{Non-development Spending}

Recall that in Table 5, we had observed that the share of total development spending was lower in the post-decentralisation period for ethnically diverse communities which did not observe Adat laws strictly. In other words, the share of total non-development spending was higher in the post-decentralisation period for these very same communities. This is our first piece of evidence of capture by the local elites in these communities in line with our theoretical predictions.

Here, we add to this by delving further into this category of spending. Both the 1997 and the 2007 rounds of the IFLS provide detailed information on village finance including both revenue and expenditure of the community government. We gather the information of the salary expenditure of village government officials. This includes the salary for the village leader, village secretary, head of different sections of the government, head of Dusun (hamlet heads of different linguistic groups) and Badan Permusyawaratan Desa (BPD or the village consultative body). We aggregate these salary expenditures to create a new variable of public 
spending, namely, the total spending on salaries. Table 3 reveals that the mean of the log of this variable is 13.424 which is comparable to the mean of the log of total development spending (the sample mean is 14.999). Hence, it is quite evident that the total spending on salaries of these local sub-district officials constitute a significant portion of the overall community-level public spending.

We posit that this spending on salaries is preferred by the elite in the community in the manner that spending on infrastructure development is preferred by the non-elite members of the community. Our claim rests on the following premises:

(a) these are items enjoyed privately by very few members of the community, namely, by the village level officials with practically little or no spillover effects, and

(b) these officials (elected or otherwise) have sufficient influence with the district-level officials which is the next higher rung of governance and also the one holding considerable power post-decentralisation.

In other words, we claim that diverting funds towards the salaries and other expenses of these local officials at the cost of lower infrastructure spending is a clear indication of a movement away from the non-elite's public spending priorities. Hence, we expect the effect on this category of spending to be the opposite of what we have observed so far.

Table 7 contains some results where the outcome variable pertains to spending on salaries of the local officials. The dependent variable in columns (1)-(3) is the log of spending on salaries of officials in the community, while in columns (4)-(6) it is the share of such salary expenditure out of the total public spending in the community. In columns (1) and (4) the sample is restricted to those communities which are not entirely ethnically homogeneous. In columns (2) and (5), the sample is restricted to fairly homogeneous communities, i.e., where the size of the largest ethnic group constitutes is at least $91 \%$ of the population. In columns (3) and (6), the sample is restricted to those communities where the largest ethnic group constitutes less than $91 \%$ of the population.

In columns (2) and (3) of Table 7, the coefficient on the triple-interaction term Non$A_{d a t^{*} F r a c}{ }^{*} F D$ is negative and statistically significant. Moreover, the magnitude of the coefficient in column (2) (i.e., the more ethnically homogeneous sample of communities) is more than twice that of the coefficient in column (3) which has the more ethnically diverse set of communities. This is in stark contrast with all the previous results.

This asymmetry is heightened when we look at the cases where the dependent variable is the share of such salary expenditure in the total public spending. Specifically, in column (5) the coefficient on Non-Adat*Frac ${ }^{*} F D$ is negative and statistically significant and it is positive and statistically significant in column (6). This suggests that being a Non-Adat and ethnically diverse community is associated with an increase in the share of salaries in total public spending in the post-decentralisation period for the more ethnically diverse set of communities. 


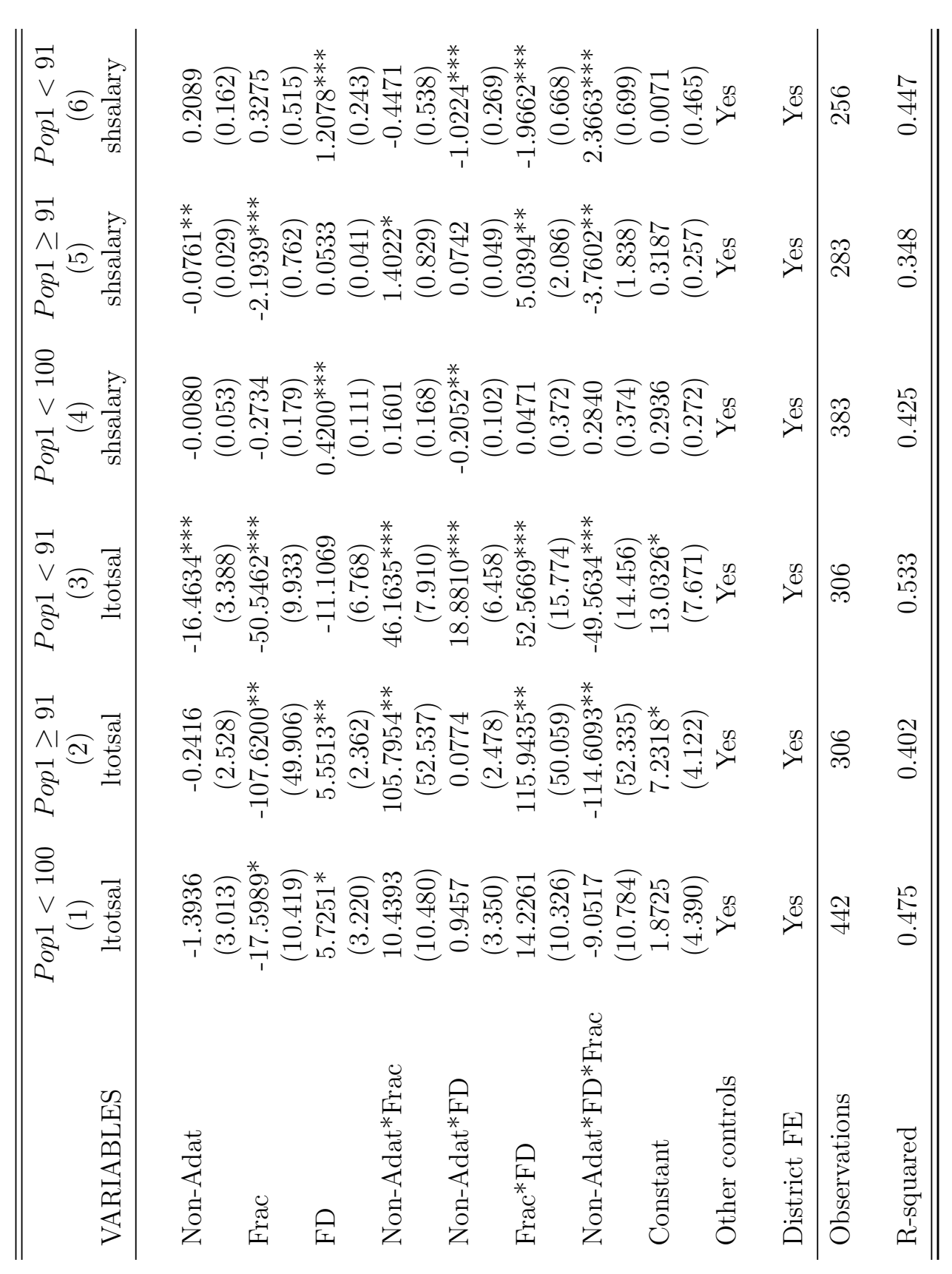

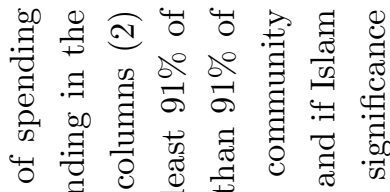

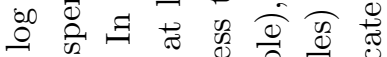

宩

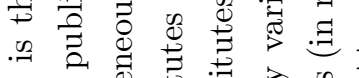

๙ิ

Є

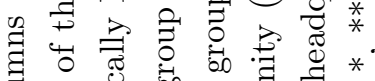

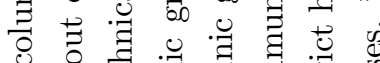

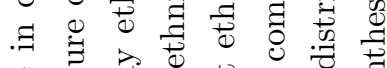

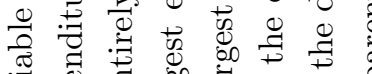

สี

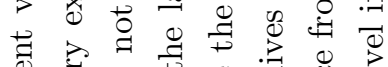

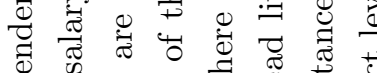

过

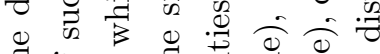

光

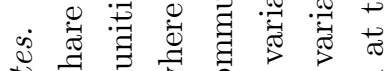

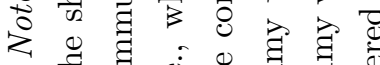

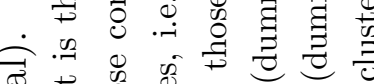

曾

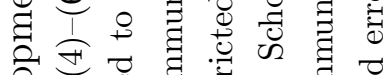

엉

总言跑

至. 0 .

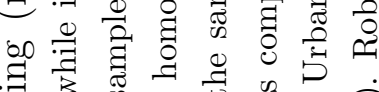

व

क $\Xi$ 西

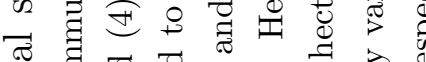

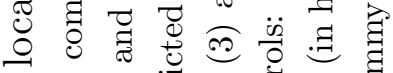

च

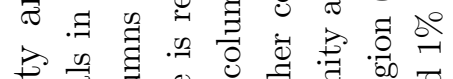

空高

点苓

‥

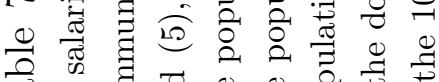

兆 
It is worthwhile to reiterate that the corresponding association with any form of development spending for the same sample of communities has been negative.

Taken together, these sets of results strongly indicate that for the more ethnically diverse set of communities (specifically, where the largest ethnic group constitutes less than $91 \%$ of the population), being a Non-Adat and ethnically diverse community leads to lower development spending (in levels and shares) and a higher share of salaries in the total public spending in the community. These results are robust to using an alternative measure of ethnic diversity. Table 12 in the Appendix replicates the findings in Table 7 using our second measure of ethnic diversity, namely, Frac1.

\subsubsection{Local leadership}

So far we did not account for the nature of local leadership in the community. As discussed earlier (see e.g., Table 1), there were a variety of methods by which communities selected their leaders. While in several communities it was fairly democratic by the use of voting or consensus-building, in several others the selection was done by the local elite (termed "oligarchy" in Table 1). While in the pre-decentralisation period the influence of these local leaders would have been limited, the same can hardly be said for the post-decentralisation years. In other words, the nature of local leadership could potentially have a bearing upon the local public spending patterns especially in the post-decentralisation period.

Our theoretical model does not explicitly account for this feature. We do assume that the leader $L$ (who is endowed with authority over spending in the post-decentralisation period) is acting in the interests of all the community members. But that refers to the districtlevel official who is 'local' in the sense of not being based in Jakarta as part of the central government. We do not explicitly model the local community leader. In reality, the district official can only implement the spending with the cooperation of the community leader. Thus, the final local level public spending is also subject to the actions of the community leader. Given this situation, our model implicitly assumes that in the absence of any lobbying the combined efforts of the district and the community leader serve the entire community and not just the interests of the local elite.

In other words, one can interpret our model as one which implicitly assumes that the local community leader is basically democratic in his/her actions.

In light of the above discussion, we expect our core results to hold in the sample of communities where the community leader is democratically elected. In the case where the community leader is hand-picked by the elite, we do not know what to expect. It may well be possible that a community dominated politically by the local elite may not register much change after fiscal decentralisation as it is equally prone to elite capture in both time periods. This is what we seek to examine here. 
To that end, using the information on leader selection from 1997 and 2007 rounds of IFLS data, we generate an index of local democratisation as follows:

Status_V $=1$ if the community selected a leader by voting or consensus building in both 1997 and 2007 or it became so only in 2007; it is zero otherwise.

Table 8 contains the results which distinguish between communities in terms of the nature of their local leadership, i.e., by Status_V. In the first four columns, we restrict attention to communities for which $S_{t a t u s_{-}} V=0$; therefore, these are communities in which the selection of the leader was done by the local elite (termed "oligarchy" in Table 1). In the last four columns, we consider only those communities for which $S_{t a t u s} V=1$; hence, here the leader is elected democratically at least in the post-decentralisation period.

The dependent variable in columns (1) and (5) is the log of Development expenditure in the community, while in columns (3) and (7) it is the same including IDT. Each of the remaining columns have - as the dependent variable - the corresponding shares out of total public spending in the community for the dependent variable in the column preceding it. Also, in all the columns the sample is restricted to those communities which are not entirely ethnically homogeneous.

In columns (1)-(4) of Table 8, we find that the coefficient on the triple-interaction term Non-Adat*Frac ${ }^{*} F D$ is not statistically significant. This suggests that in communities where the local leader is chosen by the local elite there seems to be no change in the pattern of development spending over time in Non-Adat communities which are ethnically diverse. This is true whether one considers the level of development spending or it's share out of the total public spending. In columns (5)-(8), things look quite different. Here we find the results echoing our previous findings. The coefficient on the triple-interaction term Non$A d a t^{*} F r a{ }^{*} F D$ is negative in all the columns and is statistically significant for the share of development spending. Thus it is the set of communities with democratically elected leaders which exhibit the same spending patterns as the overall sample. These results are robust to using an alternative measure of ethnic diversity. Table 13 in the Appendix replicates the findings in Table 8 using our second measure of ethnic diversity, namely, Frac1.

Taking stock of our empirical findings, we observe a robust and consistent pattern in the level and shares of different components of local public spending when viewed before and after the fiscal decentralisation event. The patterns are stable across various specifications and are consistent with the predictions of our theoretical model. These results strongly indicate that local elite capture makes its presence felt more strongly in the post-decentralisation period — via distortion in local public spending - in communities which lack sufficient internal cohesion (Non-Adat) and happen to be ethnically diverse. 


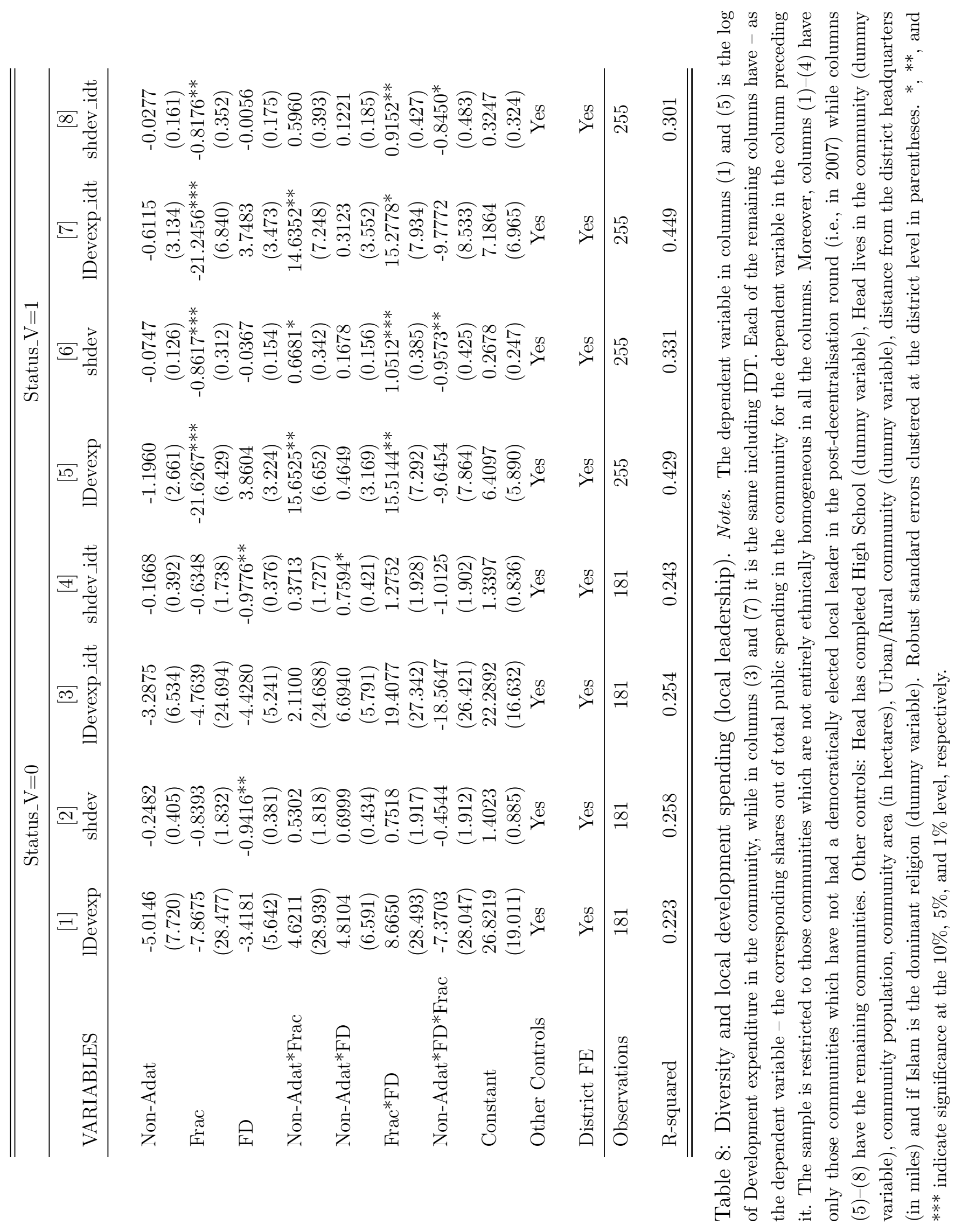




\section{Conclusion}

In this paper, we present an analysis of the trade-off between the gains from decentralisation and the losses from local elite capture in the context of an ethnically diverse society. In particular, our focus is on the salience of local institutions in this trade-off. Using the massive fiscal decentralisation programme in Indonesia which came at the end of Suharto's regime, we document some consistent empirical patterns.

To highlight how exactly ethnic diversity may affect the efficacy of the local political process, we build a simple model of lobbying where citizens may lobby the local politician to tilt the spending in their favour. The local elite is endowed with a first-mover advantage of selecting one of the ethnic groups as it's lobbying partner. Alternatively, the local elite could simply lobby alone. The lobby group if successful can dictate public spending and thereby limit to benefiting only themselves. Ethnic diversity will compound the problem as the elite would be able to exploit the differences in preferences across the ethnic groups to form a lobby. In such a scenario, any factor which serves to raise coordination across the citizens from differing ethnicities would reduce the distortion in spending and bring it more in line with the requirements of the masses.

In our empirical exercise, we identified a distinct feature of Indonesian communities which we argue is capable of affecting cooperation among the citizens. We utilise the presence of centuries-old Adat norms which emphasise consensus building among the community members and thereby reduce coordination costs and enhance cooperation. Hence, communities which did not adhere to Adat norms are more likely to have higher coordination costs across ethnic groups. Miguel and Gugerty (2005) argue how inability to impose social sanctions in diverse communities leads to collective action failures. We, in contrast, argue that ability of Adat communities to impose social sanctions had facilitated collective action in our sample. Using IFLS 2007 data, we find that individuals who break the adat rules of their community can face significant penalties, including the payment of fines, ostracism and even, in some cases, expulsion from the community. As expected, the penalties are more severe in communities which practise stronger adherence to adat laws. In our empirical analysis, we consistently found that communities which were not Adat and were ethnically diverse tended to have lower levels of development spending at the community level after controlling for a host of explanatory variables. We observe the opposite effects for what we term 'nondevelopment' spending. Taken together, these empirical findings appear consistent with the mechanisms outlined in our theory.

Our analysis highlights that fiscal and political decentralisation are not necessarily a panacea for ethnically diverse communities. The overall impact of decentralisation on community governance and consequent local development in diverse communities depends not only on the nature and extent of fiscal autonomy, but also on the prevailing local demographic and institutional features. 
It is quite possible that being a community which adheres to Adat laws makes it somewhat different in ways which can influence the trajectory of local public spending quite aside from affecting the level of cooperation and coordination costs within the community. To be sure, this other potential channel must take effect only — or at least, predominantly — in ethnically diverse communities. While there seems to be no such obvious confounding factor, it cannot be ruled out in principle and hence the need to explore these subtleties in a more nuanced manner. Nonetheless, we believe that our findings shed new light on an issue which is both intellectually stimulating and policy-relevant. 


\section{References}

Ahlerup, Pelle and Olsson, Ola (2007). "The Roots of Ethnic Diversity", Working Papers in Economics 281, University of Gothenburg, Department of Economics.

Ashraf, Q., and Galor, O. (2013) "The 'Out of Africa' Hypothesis, Human Genetic Diversity, and Comparative Economic Development." American Economic Review, 103 (1): 1-46.

Azfar, O., S. Khknen, and P. Meagher. (2001) "Conditions for Effective Decentralised Governance: A Synthesis of Research Findings", IRIS Centre, University of Maryland.

Bandiera, O. and Levy, G. (2011) "Diversity and the Power of the Elites in Democratic Societies: Evidence from Indonesia," Journal of Public Economics. 2011, vol. 95, pp. 1322 $-1330$.

Bardhan, P. (2002). "Decentralization of governance and development" , Journal of Economic Perspectives, pp. 185-205.

Bardhan, P. and D. Mookherjee (2000). "Capture and governance at local and national levels", American Economic Review, 90, pp. 135 - 139.

Bardhan, P. and D. Mookherjee (2006). "Decentralization, corruption and government accountability" in Susan Rose-Ackerman ed. International Handbook on the Economics of Corruption, Edward Elgar.

Brodjonegoro, B. (2001). "Indonesian Intergovernmental Transfer in Decentralization Era: The Case of General Allocation Fund", Paper Presented at the International Symposium on Intergovernmental Transfers in Asian Countries, Asian Tax and Public Policy Program, Hitotsubashi University, Tokyo, February 2001.

(Accessed at http://www.econ.hitu.ac.jp/kokyo/symposium/PDF/Indonesia.PDF)

Collier, Paul. (2008) "Growth Strategies for Africa." Commission on Growth and Development Working Paper; No. 9. World Bank, Washington, DC.

Davoodi, H. and H. Zou (1998). "Fiscal decentralization and economic growth: a cross country study", Journal of Urban Economics, 43, pp. 244 - $25 \%$.

De Luca, Miguel, Mark P. Jones and Maria Ines Tula. (2002). "Black rooms or ballot boxes: candidate nomination in Argentina", Comparative Political Studies, 35, pp. 413 - 436.

Easterly, William and Levine, Ross, 1997. "Africa's Growth Tragedy: Policies and Ethnic Divisions," The Quarterly Journal of Economics, MIT Press, vol. 112(4), pages 1203 - 50, November.

Enikopolov, R. and Zhuravskaya, E. (2007). "Decentralization and political institutions" , Journal of Public Economics, 91, pp. 2261 - 2290.

Esteban, J., and D. Ray (1999). "Conflict and Distribution," Journal of Economic Theory, $87(2), 379-415$. 
Esteban, J., and D. Ray (2008). "On the Salience of Ethnic Conflict", American Economic Review, 98(5), 2185 - 2202.

Fishman, R. and R. Gatti (2002). "Decentralization and corruption: evidence across countries", Journal of Public Economics, 83, pp. $325-346$.

Frankenberg,E. and D. Thomas (2000). The Indonesia Family Life Survey (IFLS): Study design and results from waves 1 and 2.

Gomes, J.F. (2020), "The health costs of ethnic distance: evidence from sub-Saharan Africa." Journal of Economic Growth 25, 195226 (2020). https://doi.org/10.1007/s10887-020-091774

Grossman, G. M. and E. Helpman (1996). "Electoral Competition and Special Interest Politics", Review of Economic Studies (1996), 63, pp. 265 - 286.

Kato, T. (1989). "Different Fields, Similar Locusts: Adat Communities, and the Village Law of 1979 in Indonesia", Indonesia, Vol. 47, pp. 89-114.

Martinez-Bravo, M. (2014). "The Role of Local Officials in New Democracies: Evidence from Indonesia", American Economic Review, 104(4) (2014), 1-45.

Martinez-Bravo, M., P. Mukherjee and A. Stegmann (2017). "The Non-Democratic Roots of Elite Capture: Evidence from Soeharto Mayors in Indonesia". Econometrica, 85 (6), 1991-2010.

Michalopoulos, S. (2012). "The Origins of Ethnolinguistic Diversity", The American Economic Review Vol. 102, No. 4, pp. 1508-1539.

Miguel, E. and Gugerty, M.K. (2005). "Ethnic diversity, social sanctions, and public goods in Kenya", Journal of Public Economics, Volume 89, Issues 1112, 2005, Pages 2325-2368.

Mill, John Stuart (1861) "Considerations on Representative Government", London: Parker.

Olken, B. (2007). "Political Institutions and Local Public Goods", mimeo, Harvard University, February.

Padro-i-Miguel, G., N. Qian and Y. Yao. (2014). "Social Fragmentation, Public Goods and Elections: Evidence from China", CEPR Discussion Paper No. DP8975.

Pal,S. and Wahhaj, Z. (2017). "Fiscal decentralisation, local institutions and public good provision: Evidence from Indonesia", Journal of Comparative Economics, Volume 45, Issue 2, 2017, Pages 383-409.

Strauss, J., Witoelar, F., Sikoki, B. and Anna Marie Wattie (2009). The fourth wave of the Indonesian Family Life Survey (IFLS4): Overview and Field Report.

Taylor, Charles L. and Michael C. Hudson (1972) "World Handbook of Political and Social Indicators" (Ann Arbor, MI: ICPSR). 


\section{Appendix}

Derivations of E's optimal effort levels for the three cases.

Consider Case (A). E's problem is to choose the effort level $e$ to maximise

$$
\left[\frac{1}{\lambda e+1}\right] R \alpha \beta+\left[\frac{\lambda e}{\lambda e+1}\right] \frac{R}{\lambda}-\psi e .
$$

Notice that the objective function is strictly concave in $e$ as $1 / \lambda>\alpha \beta$. Here the FOC for $E$ is given by:

$$
\frac{R(1-\lambda \alpha \beta)}{(\lambda e+1)^{2}}=\psi
$$

Hence, we get

$$
e_{0}=\frac{\left[\frac{R}{\psi}(1-\alpha \beta \lambda)\right]^{1 / 2}-1}{\lambda}
$$

Next consider Case (B). Here, the payoff to $E$ is given by

$$
\left(\frac{[\lambda+\rho(1-\lambda)] e}{[\lambda+\rho(1-\lambda)] e+1}\right)\left(\frac{R \alpha \theta}{\lambda+\rho(1-\lambda)}\right)+\left(\frac{1}{[\lambda+\rho(1-\lambda)] e+1}\right) R \alpha \beta-\psi e .
$$

So $E$ will choose an effort level to maximise this objective function.

Notice that the objective function is strictly concave in $e$ whenever $\alpha \theta>1$. Here the FOC for $E$ is given by:

$$
\frac{R \alpha(\theta-\beta[\lambda+(1-\lambda) \rho])}{([\lambda+(1-\lambda) \rho] e+1)^{2}}=\psi
$$

Hence, we get

$$
e_{1}=\frac{\left[\frac{R \alpha}{\psi}(\theta-\beta[\lambda+(1-\lambda) \rho])\right]^{1 / 2}-1}{\lambda+(1-\lambda) \rho}
$$

Analogous steps generate the corresponding expression for case (C).

Proof. [LEMma 1.] From the FOC for the $E \cup C_{1}$ case, we have

$$
\frac{R \alpha}{\psi}(\theta-\beta[\lambda+(1-\lambda) \rho])=([\lambda+(1-\lambda) \rho] e+1)^{2} .
$$

The solution is denoted by $e_{1}$. Similarly, for the $E \cup C_{2}$ case, we have

$$
\frac{R \alpha}{\psi}(\theta-\beta[\lambda+(1-\lambda)(1-\rho)])=([\lambda+(1-\lambda)(1-\rho)] e+1)^{2} .
$$


The solution is denoted by $e_{2}$. Since, $\rho \in[1 / 2,1)$ it must be that

$$
[\lambda+(1-\lambda) \rho] e_{1} \leq[\lambda+(1-\lambda)(1-\rho)] e_{2} .
$$

This implies $e_{1}<e_{2}$ for $\rho \in(1 / 2,1)$ and $e_{1}=e_{2}$ for $\rho=1 / 2$.

Proof. [observation 1.] Take any $\rho \in(1 / 2,1)$. Let

$$
U_{1}(e) \equiv\left(\frac{e}{[\lambda+\rho(1-\lambda)] e+1}\right) R \alpha \theta+\left(\frac{1}{[\lambda+\rho(1-\lambda)] e+1}\right) R \alpha \beta .
$$

Similarly, let

$$
U_{2}(e) \equiv\left(\frac{e}{[\lambda+(1-\rho)(1-\lambda)] e+1}\right) R \alpha \theta+\left(\frac{1}{[\lambda+(1-\rho)(1-\lambda)] e+1}\right) R \alpha \beta .
$$

Hence, E's payoff from $E \cup C_{1}$ is given by $U_{1}(e)-\psi e$. Similarly, $E$ 's payoff from $E \cup C_{2}$ is given by $U_{2}(e)-\psi e$.

Note, $U_{1}\left(e_{1}\right)<U_{2}\left(e_{1}\right)$ since $\rho \in(1 / 2,1)$. Hence,

$$
U_{1}\left(e_{1}\right)-\psi e_{1}<U_{2}\left(e_{1}\right)-\psi e_{1} .
$$

By definition,

$$
U_{2}\left(e_{1}\right)-\psi e_{1} \leq U_{2}\left(e_{2}\right)-\psi e_{2} .
$$

Hence,

$$
U_{1}\left(e_{1}\right)-\psi e_{1}<U_{2}\left(e_{1}\right)-\psi e_{1} \leq U_{2}\left(e_{2}\right)-\psi e_{2} .
$$

This completes the proof.

Proof. [obSERvation 2.] The payoff to $E$ from $E \cup C_{2}$ is

$$
\left(\frac{e}{[\lambda+(1-\rho)(1-\lambda)] e+1}\right) R \alpha \theta+\left(\frac{1}{[\lambda+(1-\rho)(1-\lambda)] e+1}\right) R \alpha \beta-\psi e .
$$

Setting $\rho=1$, implies that the above becomes

$$
\left(\frac{e}{\lambda e+1}\right) R \alpha \theta+\left(\frac{1}{\lambda e+1}\right) R \alpha \beta-\psi e .
$$

Recall the expression for E's payoff when lobbying alone. It is

$$
\left[\frac{1}{\lambda e+1}\right] R \alpha \beta+\left[\frac{\lambda e}{\lambda e+1}\right] \frac{R}{\lambda}-\psi e
$$


which on simplification becomes

$$
\left(\frac{e}{\lambda e+1}\right) R+\left(\frac{1}{\lambda e+1}\right) R \alpha \beta-\psi e
$$

As $\alpha \theta>1, E^{\prime} s$ payoff from $E \cup C_{2}$ for $\rho=1$ is strictly higher than that from lobbying alone. Notice, that the payoff to $E$ from $E \cup C_{2}$ is continuous and (by Observation 1) monotonically decreasing in $\rho$. Hence, there exists a unique $\hat{\rho} \in(0,1)$ such that $E$ 's payoff from lobbying jointly with $C_{2}$ exceeds the one from lobbying alone for every $\rho \in(\hat{\rho}, 1)$.

Proof. [Lemma 2.] Consider the case of $E \cup C_{2}$. The payoff to $E$ from $E \cup C_{2}$ is

$$
\pi_{E}\left(E \cup C_{2}\right) \equiv\left(\frac{e}{[\lambda+(1-\rho)(1-\lambda)] e+1}\right) R \alpha \theta+\left(\frac{1}{[\lambda+(1-\rho)(1-\lambda)] e+1}\right) R \alpha \beta-\psi e .
$$

Observe that it is dependent on $\theta$. Moreover, the optimal effort $e_{2}$ is increasing in $\theta$. Let $\bar{\theta}>\underline{\theta}>1 / \alpha$ with corresponding optimal effort levels $\overline{e_{2}}>\underline{e_{2}}$. By definition,

$$
\pi_{E}\left(E \cup C_{2} ; \bar{\theta}, \overline{e_{2}}\right) \geq \pi_{E}\left(E \cup C_{2} ; \bar{\theta}, \underline{e_{2}}\right) .
$$

In addition, we have

$$
\pi_{E}\left(E \cup C_{2} ; \bar{\theta}, \underline{e_{2}}\right)>\pi_{E}\left(E \cup C_{2} ; \underline{\theta}, \underline{e_{2}}\right) .
$$

Combining these, we get

$$
\pi_{E}\left(E \cup C_{2} ; \bar{\theta}, \overline{e_{2}}\right)>\pi_{E}\left(E \cup C_{2} ; \underline{\theta}, \underline{e_{2}}\right) .
$$

Hence, the payoff to $E$ from $E \cup C_{2}$ is increasing in $\theta$. The arguments for the case of $E \cup C_{1}$ are analogous.

Proof. [observation 3.] When $\rho=1 / 2, E$ is indifferent between lobbying with $C_{1}$ or $C_{2}$. Let $e^{*}$ denote the optimal effort choice by $E$ for joint lobbying in that situation.

Note that for $\alpha \theta=1$,

$$
\left(\frac{e^{*}}{\lambda e^{*}+1}\right) R+\left(\frac{1}{\lambda e^{*}+1}\right) R \alpha \beta-\psi e^{*}>\left(\frac{e^{*}}{\left(\frac{\lambda+1}{2}\right) e^{*}+1}\right) R \alpha \theta+\left(\frac{1}{\left(\frac{\lambda+1}{2}\right) e^{*}+1}\right) R \alpha \beta-\psi e^{*}
$$

given that $\lambda \in(0,1 / 2)$.

Observe that the LHS is $\pi_{E}\left(E ; e^{*}\right)$ while the RHS is $\pi_{E}\left(E \cup C_{1}\right)=\pi_{E}\left(E \cup C_{2}\right)$ since $\rho=1 / 2$. Hence for $\alpha \theta=1$,

$$
\pi_{E}\left(E ; e_{0}\right) \geq \pi_{E}\left(E ; e^{*}\right)>\pi_{E}\left(E \cup C_{1} ; e^{*}, \rho=1 / 2\right)
$$

where the first (weak) inequality follows from definition. 
Given that $\pi_{E}\left(E ; e_{0}\right)$ is independent of $\theta$ and $\pi_{E}\left(E \cup C_{1} ; e^{*}, \rho=1 / 2\right)$ is increasing in $\theta$ (by Lemma 2), there must be a unique $\theta-$ call it $\theta^{*}$ - such that

$$
\pi_{E}\left(E ; e_{0}\right)=\pi_{E}\left(E \cup C_{1} ; e^{*}, \rho=1 / 2\right)
$$

when $\theta=\theta^{*}$. Hence, for every $\theta<\theta^{*}$ we have $\pi_{E}\left(E ; e_{0}\right)>\pi_{E}\left(E \cup C_{1}\right)$ when $\rho=1 / 2$.

Moreover, by Observation 1 we have that $\pi_{E}\left(E \cup C_{1}\right)$ is decreasing in $\rho$. Thus, for every $\theta<\theta^{*}$ we have $\pi_{E}\left(E ; e_{0}\right)>\pi_{E}\left(E \cup C_{1}\right)$ when $\rho \in[1 / 2,1)$, thereby completing the proof.

Proof. [observation 4.] For $C_{2}$ to prefer lobbying over staying out, the following must hold

$$
\pi_{C_{2}}\left(E \cup C_{2}\right) \geq\left(\frac{R \alpha \beta}{\lambda e_{0}+1}\right),
$$

where the RHS denotes the payoff to $C$ when $E$ lobbies alone and fails, and

$\pi_{C_{2}}\left(E \cup C_{2}\right) \equiv\left(\frac{e_{2}}{[\lambda+(1-\rho)(1-\lambda)] e_{2}+1}\right) R \alpha s_{2}+\left(\frac{1}{[\lambda+(1-\rho)(1-\lambda)] e_{2}+1}\right) R \alpha \beta-\psi e_{2}$,

where

$$
s_{2}=1-\frac{\lambda(\theta-1)}{(1-\lambda)(1-\rho)} .
$$

The above inequality can be written as

$e_{2}\left[\left(\frac{1}{[\lambda+(1-\rho)(1-\lambda)] e_{2}+1}\right) R \alpha s_{2}-\psi\right] \geq R \alpha \beta\left[\frac{1}{\lambda e_{0}+1}-\frac{1}{[\lambda+(1-\rho)(1-\lambda)] e_{2}+1}\right]$,

where

$$
e_{2}=\frac{\left[\frac{R \alpha}{\psi}(\theta-\beta[\lambda+(1-\lambda)(1-\rho)])\right]^{1 / 2}-1}{\lambda+(1-\lambda)(1-\rho)} .
$$

Hence, the LHS can be re-written as

$$
e_{2} \psi^{1 / 2}\left[\left(\frac{(R \alpha)^{1 / 2} s_{2}}{(\theta-\beta[\lambda+(1-\lambda)(1-\rho)])^{1 / 2}}\right)-\psi^{1 / 2}\right] .
$$

Now consider the case where $\frac{(\theta-1)}{(1-\rho)}<\frac{(1-\lambda)}{\lambda}$. Hence, $s_{2}>0$. Note, $\forall \psi>0$,

$$
e_{2} \psi^{1 / 2}\left[\left(\frac{(R \alpha)^{1 / 2} s_{2}}{(\theta-\beta[\lambda+(1-\lambda)(1-\rho)])^{1 / 2}}\right)-\psi^{1 / 2}\right]
$$

is falling in $\psi$.

Moreover, as $\psi \rightarrow 0$ both $\lambda e_{0}+1$ and $[\lambda+(1-\rho)(1-\lambda)] e_{2}+1$ approach infinity (follows 
from their definitions). Hence, by making $\psi$ arbitrarily close to 0 ,

$$
\left[\frac{1}{\lambda e_{0}+1}-\frac{1}{[\lambda+(1-\rho)(1-\lambda)] e_{2}+1}\right]
$$

can be made to approach 0 . This implies that there exists $\bar{\psi}(\rho)>0$ such that for $\psi=\bar{\psi}(\rho)$ the following holds:

$e_{2} \psi^{1 / 2}\left[\left(\frac{(R \alpha)^{1 / 2} s_{2}}{(\theta-\beta[\lambda+(1-\lambda)(1-\rho)])^{1 / 2}}\right)-\psi^{1 / 2}\right]=R \alpha \beta\left[\frac{1}{\lambda e_{0}+1}-\frac{1}{[\lambda+(1-\rho)(1-\lambda)] e_{2}+1}\right]$

and for all $\psi<\bar{\psi}(\rho)$,

$e_{2} \psi^{1 / 2}\left[\left(\frac{(R \alpha)^{1 / 2} s_{2}}{(\theta-\beta[\lambda+(1-\lambda)(1-\rho)])^{1 / 2}}\right)-\psi^{1 / 2}\right]>R \alpha \beta\left[\frac{1}{\lambda e_{0}+1}-\frac{1}{[\lambda+(1-\rho)(1-\lambda)] e_{2}+1}\right]$.

Define $\underline{\psi}$ to be the $\lim \inf \{\bar{\psi}(\rho): \rho \in[1 / 2,1)\}$. This proves the first part of the observation.

Now consider the case where $\frac{(\theta-1)}{(1-\rho)} \geq \frac{(1-\lambda)}{\lambda}$. Hence, $s_{2}=0$. Here for every $\psi>0$

$$
e_{2} \psi^{1 / 2}\left[-\psi^{1 / 2}\right]<R \alpha \beta\left[\frac{1}{\lambda e_{0}+1}-\frac{1}{[\lambda+(1-\rho)(1-\lambda)] e_{2}+1}\right] .
$$

Hence, $C_{2}$ will prefer to stay out than lobby with $E$.

Proof. [obSERVATion 5.] Recall $e_{0}=\frac{\left[\frac{R}{\psi}(1-\alpha \beta \lambda)\right]^{1 / 2}-1}{\lambda}$. Hence,

$$
p_{0} \equiv \frac{\lambda e_{0}}{\lambda e_{0}+1}=\frac{\left[\frac{R}{\psi}(1-\alpha \beta \lambda)\right]^{1 / 2}-1}{\left[\frac{R}{\psi}(1-\alpha \beta \lambda)\right]^{1 / 2}} \text {. }
$$

Also, $e_{2}=\frac{\left[\frac{R \alpha}{\psi}(\theta-\beta[\lambda+(1-\lambda)(1-\rho)])\right]^{1 / 2}-1}{\lambda+(1-\lambda)(1-\rho)}$ implies

$$
p_{2} \equiv \frac{[\lambda+(1-\lambda)(1-\rho)] e_{2}}{[\lambda+(1-\lambda)(1-\rho)] e_{2}+1}=\frac{\left[\frac{R \alpha}{\psi}(\theta-\beta[\lambda+(1-\lambda)(1-\rho)])\right]^{1 / 2}-1}{\left[\frac{R \alpha}{\psi}(\theta-\beta[\lambda+(1-\lambda)(1-\rho)])\right]^{1 / 2}} .
$$

Observe that for $i=0,2$,

$$
p_{i}=\frac{x_{i}-1}{x_{i}}
$$

where $x_{0}=\left[\frac{R}{\psi}(1-\alpha \beta \lambda)\right]^{1 / 2}$ and $x_{2}=\left[\frac{R \alpha}{\psi}(\theta-\beta[\lambda+(1-\lambda)(1-\rho)])\right]^{1 / 2}$.

Moreover, $p_{i}$ is increasing in $x_{i}$. Hence we need to simply compare $x_{0}$ and $x_{2}$ to ascertain 
which of the two $p_{i}$ 's is greater. As $\rho \rightarrow 1$, by $\alpha \theta>1$ we have

$$
\frac{R \alpha}{\psi}(\theta-\beta[\lambda+(1-\lambda)(1-\rho)])>\frac{R}{\psi}(1-\alpha \beta \lambda) .
$$

This establishes part (i).

For part (ii), note that $\frac{R \alpha}{\psi}(\theta-\beta[\lambda+(1-\lambda)(1-\rho)])$ is increasing in $\rho$. This implies $p_{2}$ falls as $\rho$ falls. As $p_{0}$ is independent of $\rho$, we have that $p_{0} / p_{2}$ increases as $\rho$ falls.

Proof. [observation 6.] This is clear from inspecting $e_{0}, e_{1}$ and $e_{2}$. 


\begin{tabular}{|c|c|c|c|c|}
\hline VARIABLES & $\begin{array}{c}(1) \\
\text { Pop } 1<100\end{array}$ & $\begin{array}{c}(2) \\
\text { Pop } 1<91\end{array}$ & $\begin{array}{c}(3) \\
\text { Pop } 1<100\end{array}$ & $\begin{array}{c}(4) \\
\text { Pop } 1<91\end{array}$ \\
\hline & Non-Adat only & $\underline{\text { Non-Adat only }}$ & & \\
\hline Non-Adat & & & $\begin{array}{c}-2.6778 \\
(2.595)\end{array}$ & $\begin{array}{c}-16.1073^{* * *} \\
(3.706)\end{array}$ \\
\hline Frac & $\begin{array}{c}-4.8992^{* *} \\
(2.012)\end{array}$ & $\begin{array}{l}0.7292 \\
(3.550)\end{array}$ & $\begin{array}{c}-19.7206^{* *} \\
(7.848)\end{array}$ & $\begin{array}{c}-48.3215^{* * *} \\
(8.118)\end{array}$ \\
\hline FD & $\begin{array}{c}4.3796^{* * *} \\
(0.973)\end{array}$ & $\begin{array}{c}7.8936^{* * *} \\
(2.257)\end{array}$ & $\begin{array}{l}1.2802 \\
(3.203)\end{array}$ & $\begin{array}{c}-19.8040^{* *} \\
(7.298)\end{array}$ \\
\hline Non-Adat*Frac & & & $\begin{array}{c}14.7461^{*} \\
(8.081)\end{array}$ & $\begin{array}{c}48.6404^{* * * *} \\
(9.088)\end{array}$ \\
\hline Non-Adat*FD & & & $\begin{array}{l}3.0953 \\
(3.131)\end{array}$ & $\begin{array}{c}27.4997^{* * * *} \\
\quad(8.346)\end{array}$ \\
\hline Frac*FD & $\begin{array}{l}0.4613 \\
(2.110)\end{array}$ & $\begin{array}{c}-6.5544^{*} \\
(3.439)\end{array}$ & $\begin{array}{c}15.9491^{*} \\
(9.497)\end{array}$ & $\begin{array}{c}69.4174^{* * *} \\
(16.293)\end{array}$ \\
\hline Non-Adat*FD*Frac & & & $\begin{array}{c}-15.5418 \\
(9.757)\end{array}$ & $\begin{array}{c}-75.5729^{* * *} \\
(17.348)\end{array}$ \\
\hline Constant & $\begin{array}{c}8.6267^{* *} \\
(4.205)\end{array}$ & $\begin{array}{l}0.5072 \\
(4.778)\end{array}$ & $\begin{array}{c}10.5497^{*} \\
(5.610)\end{array}$ & $\begin{array}{c}17.0534^{* * *} \\
(5.757)\end{array}$ \\
\hline Other controls & Yes & Yes & Yes & Yes \\
\hline District FE & Yes & Yes & Yes & Yes \\
\hline Observations & 413 & 288 & 436 & 300 \\
\hline R-squared & 0.254 & 0.291 & 0.263 & 0.300 \\
\hline
\end{tabular}

Table 9: Diversity and local development spending (robustness). Notes. The dependent variable in columns (1) through (4) is the log of Development expenditure in the community including IDT, i.e., lDevexp_IDT. Local institution is proxied by Non - adat in all the columns. In the first two columns, we restrict the sample to those communities which do not strictly adhere to Adat norms in both rounds (i.e., 1997 and 2007), hence Non - Adat communities. In the remaining two columns, we utilise both Adat and Non - Adat communities. In columns (1) and (3) the sample is restricted to those communities which are not entirely ethnically homogeneous, hence Pop $1<100$; and in columns (2) and (4) the sample is restricted to those communities where the largest ethnic group constitutes less than $91 \%$ of the population, hence Pop $1<91$. Other controls: Head has completed High School (dummy variable), Head lives in the community (dummy variable), community population, community area (in hectares), Urban/Rural community (dummy variable), distance from the district headquarters (in miles) and if Islam is the dominant religion (dummy variable). Robust standard errors clustered at the district level in parentheses. *, **, and *** indicate significance at the $10 \%, 5 \%$, and $1 \%$ level, respectively. 


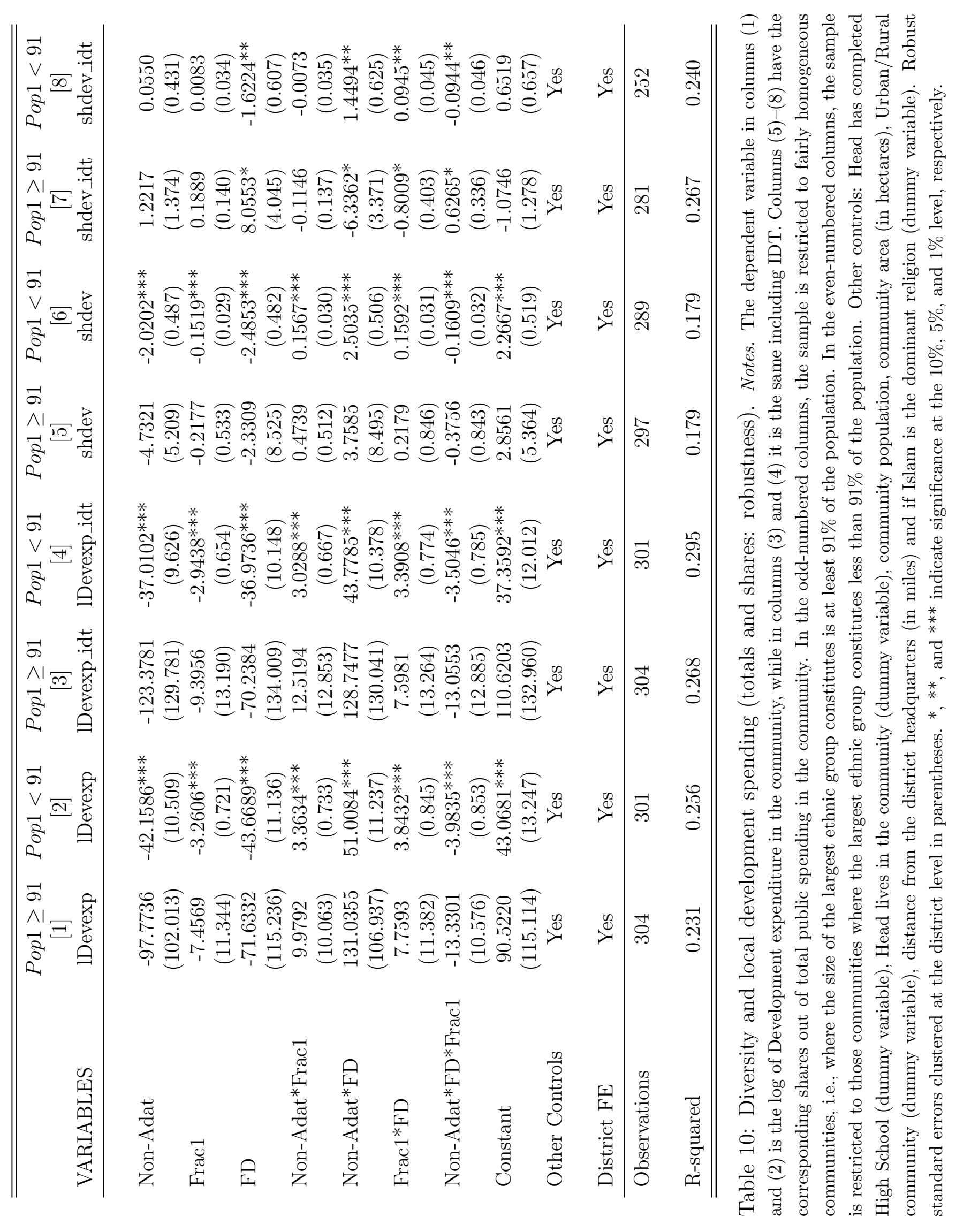




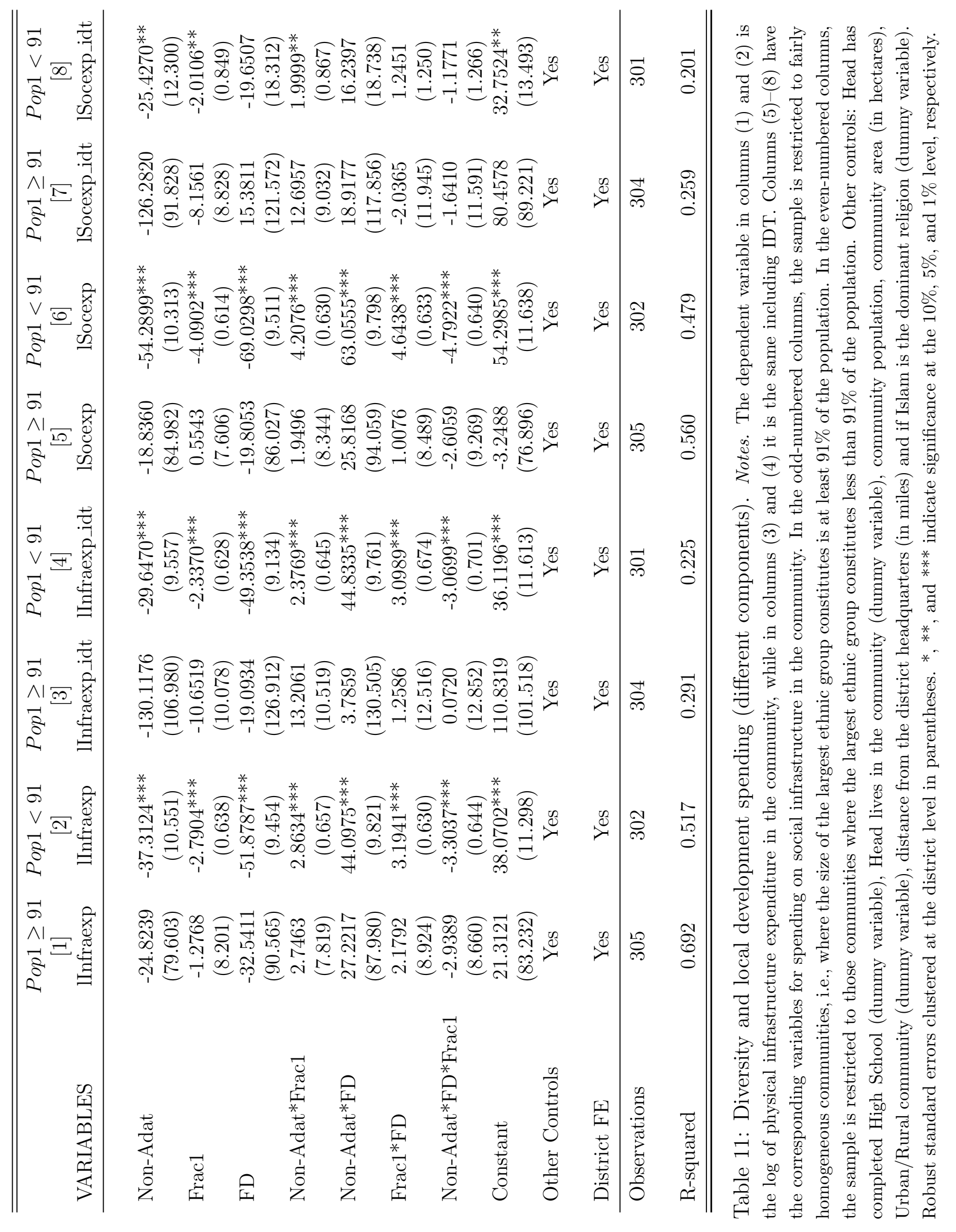




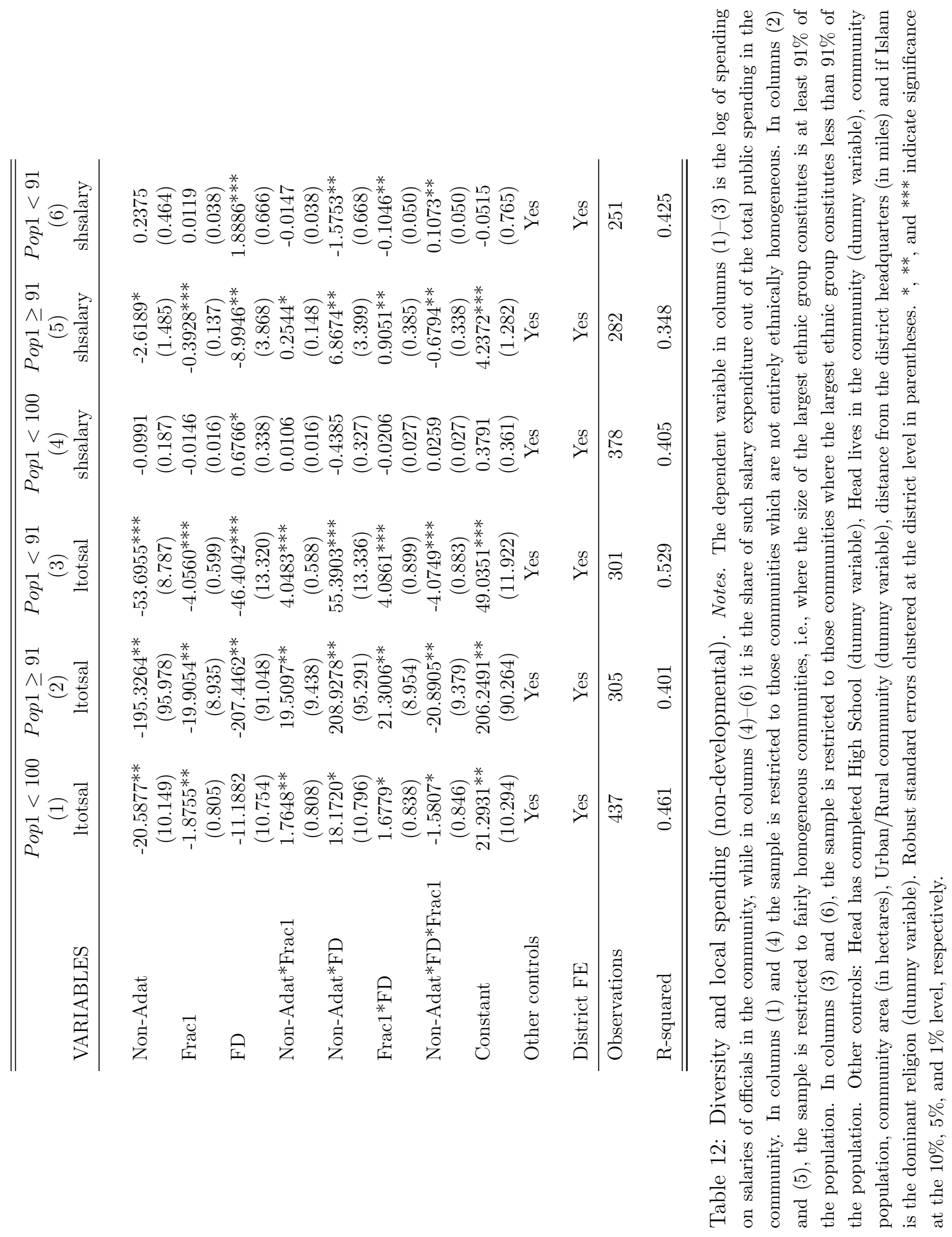




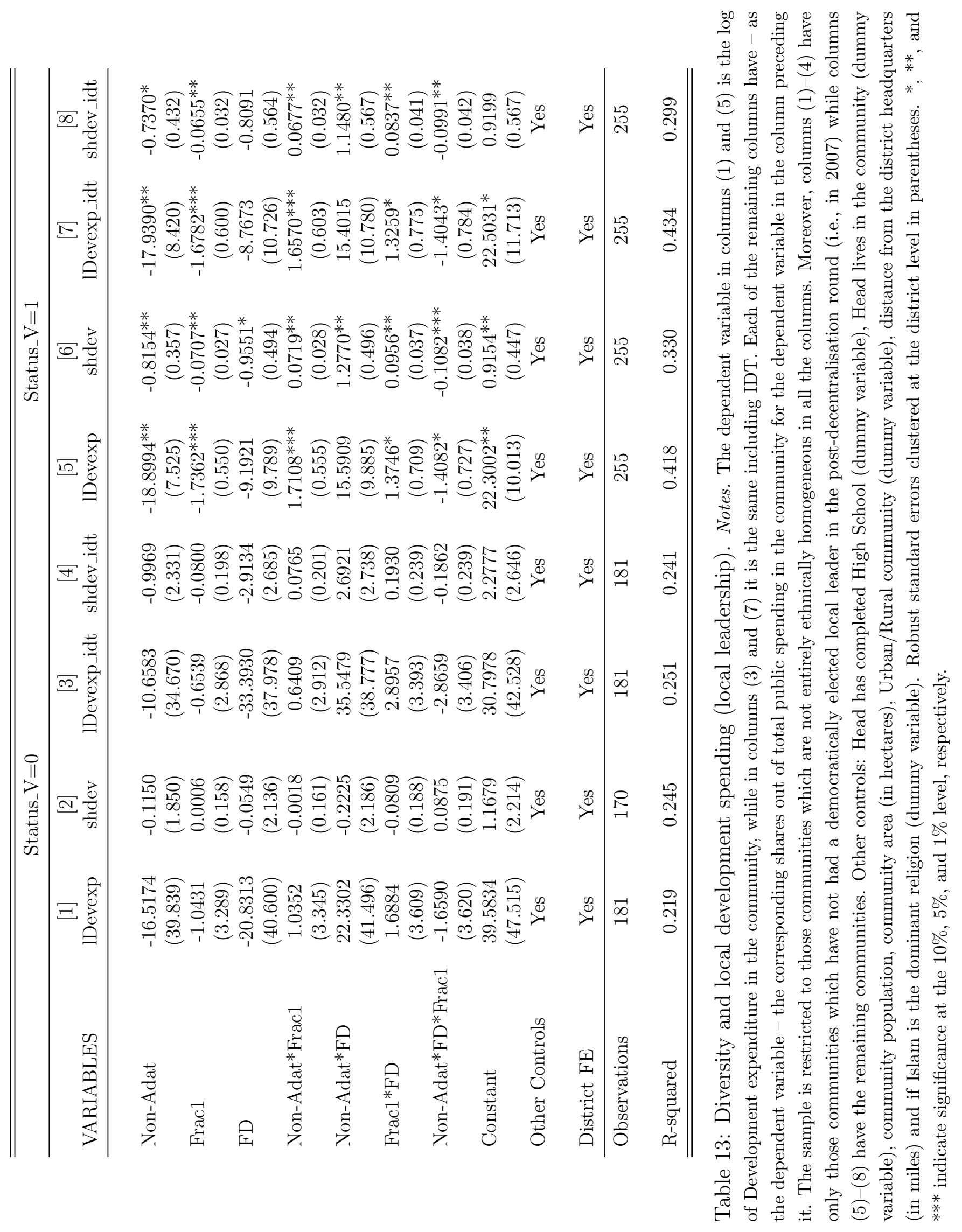

